NBER WORKING PAPER SERIES

\title{
AMBIGUITY ATTITUDES ABOUT INVESTMENTS: EVIDENCE FROM THE FIELD
}

\author{
Kanin Anantanasuwong \\ Roy Kouwenberg \\ Olivia S. Mitchell \\ Kim Peijnenberg \\ Working Paper 25561 \\ http://www.nber.org/papers/w25561 \\ NATIONAL BUREAU OF ECONOMIC RESEARCH \\ 1050 Massachusetts Avenue \\ Cambridge, MA 02138 \\ February 2019
}

This project received funding from NETSPAR, Wharton School's Pension Research Council/ Boettner Center, and Labex Ecodex. The authors thank Stephen Dimmock and Peter Wakker for helpful comments. The content is solely the responsibility of the authors and does not represent the official views of the TIAA Institute, the Wharton School's Pension Research Council/ Boettner Center, or the individuals named above. The views expressed herein are those of the authors and do not necessarily reflect the views of the National Bureau of Economic Research.

At least one co-author has disclosed a financial relationship of potential relevance for this research. Further information is available online at http://www.nber.org/papers/w25561.ack

NBER working papers are circulated for discussion and comment purposes. They have not been peer-reviewed or been subject to the review by the NBER Board of Directors that accompanies official NBER publications.

(C) 2019 by Kanin Anantanasuwong, Roy Kouwenberg, Olivia S. Mitchell, and Kim Peijnenberg. All rights reserved. Short sections of text, not to exceed two paragraphs, may be quoted without explicit permission provided that full credit, including $\odot$ notice, is given to the source. 
Ambiguity Attitudes about Investments: Evidence from the Field

Kanin Anantanasuwong, Roy Kouwenberg, Olivia S. Mitchell, and Kim Peijnenberg

NBER Working Paper No. 25561

February 2019

JEL No. C93,D14,D81

\begin{abstract}
$\underline{\text { ABSTRACT }}$
Using an incentivized survey and a representative sample of investors, we elicit ambiguity attitudes toward a familiar company stock, a local stock index, a foreign stock index, and a crypto currency. We separately estimate ambiguity aversion (ambiguity preferences) and perceived ambiguity levels (perceptions about ambiguity), while controlling for unknown likelihood beliefs. We show that ambiguity aversion is highly correlated across different assets and can be summarized by a single underlying factor. By contrast, individuals' perceived ambiguity levels differ depending on the type of asset and cannot be summarized by a single underlying factor. Perceived ambiguity is mitigated by financial literacy and education, while the preference component is correlated with risk aversion. Perceived ambiguity proves to be related to actual investment choices, validating our measure. Finally, our results imply that policies enhancing financial literacy and knowledge of financial markets can help stimulate equity market participation and reduce inequality, as these reduce peoples' perceived levels of ambiguity about financial assets.

Kanin Anantanasuwong

Mahidol University

College of Management

69 Vipawadee Rangsit Rd.

Bangkok 10400

Thailand

kaninanant@gmail.com

Roy Kouwenberg

College of Management

Mahidol University

69 Vipawadee Rangsit Rd

Bangkok, 10400, Thailand

and Erasmus University Rotterdam

cmroy@mahidol.ac.th

Olivia S. Mitchell

University of Pennsylvania

The Wharton School

3620 Locust Walk, St 3000 SH-DH

Philadelphia, PA 19104-6302

and NBER

mitchelo@wharton.upenn.edu

Kim Peijnenberg

EDHEC

393 Promenade des Anglais

Nice 06200

France

kim.peijnenburg@edhec.edu
\end{abstract}




\section{Introduction}

Households often confront financial decision problems such as investment and insurance choices where the probability distribution of the outcomes is not precisely known. Ambiguity refers to such situations where the probabilities are unknown, whereas risk refers to known probabilities. A large theoretical literature suggests that ambiguity aversion can explain several puzzling features of household financial decision-making such as low stock market participation and investment home bias. ${ }^{1}$ Only recently has the relation between ambiguity aversion and household financial choices been tested empirically (see, e.g., Dimmock, Kouwenberg, and Wakker, 2016; Dimmock, Kouwenberg, Mitchell, and Peijnenburg, 2016; and Bianchi and Tallon, 2018). To avoid reverse causality, ambiguity attitudes are typically measured in these studies using artificial events based on Ellsberg urn experiments, rather than the ambiguous investment return distributions that households actually face. ${ }^{2}$ As a result, much is known about people's ambiguity aversion for artificial Ellsberg urns, but very little about ambiguity attitudes toward real world investments.

In this paper, we measure ambiguity attitudes toward return distributions that investors typically face when making portfolio choices. We employ a new method devised by Baillon, Huang, Selim, and Wakker (2018b) to elicit ambiguity attitudes for these natural sources of ambiguity instead of artificial events, while controlling for unknown probability beliefs. This method overcomes the well-known problem that, when observing a dislike of ambiguous options, this could be due either to ambiguity aversion or to pessimistic beliefs. We field a purpose-built

\footnotetext{
${ }^{1}$ Among others, see Dow and Werlang (1992), Cao, Wang, and Zhang (2005), Easley and O'Hara (2009), Garlappi, Uppal, and Wang (2007), Bossaerts, Ghirardato, Guarnaschelli, and Zame (2010), Epstein and Schneider (2010), and Peijnenburg (2018).

2 Theory predicts that investors with higher ambiguity aversion are less likely to invest in unfamiliar assets such as foreign stocks. Yet the act of investing in these assets can also lead to lower ambiguity aversion. To circumvent reverse causality issues, empirical tests therefore use ambiguity aversion toward artificial Ellsberg urns as a proxy. Further, most available methods for measuring ambiguity attitudes require separate measurements of a person's beliefs about the unknown probabilities, which is difficult to do unless simple artificial sources like Ellsberg urns are used.
} 
survey module to elicit ambiguity attitudes in a representative sample of about 300 Dutch investors in the De Nederlandse Bank (DNB) Household Survey (DHS). At the individual level, we estimate both preferences toward ambiguity and perceived levels of ambiguity about a familiar individual stock, the local stock market index, a foreign stock market index, and the crypto-currency Bitcoin. Our paper is the first to provide information about ambiguity attitudes toward several financial assets in a large representative sample of investors.

We find that, on average, about $65 \%$ of the investors are ambiguity averse toward the four investments, although a sizeable fraction (30\%) is ambiguity seeking. Furthermore, the correlations between the ambiguity aversion measures for the four investments are high, ranging from 0.63 to 0.74 . Factor analysis shows that a single factor can explain $77 \%$ of the cross-sectional variation, indicating that a single underlying preference variable is driving ambiguity aversion toward these different financial sources. This implies that if an investor has relatively high ambiguity aversion toward one specific financial asset (e.g., the local stock index, or a familiar stock), he also tends to display high ambiguity aversion toward other investments as well (e.g., a foreign stock index or Bitcoin). In contrast, we find that investors' perceived levels of ambiguity differ substantially for each investment and cannot be summarized by a single measure. Thus the same investor may perceive low ambiguity about a familiar company stock but perceive high ambiguity about Bitcoin. These results have important implications for models of ambiguity applied in finance, suggesting that a single parameter is sufficient to capture ambiguity preferences, while perceived ambiguity is source-dependent.

Our large-scale survey also allows us to assess the relation between investor characteristics and ambiguity attitudes in the population, instead of subjects in lab experiments. We find that perceived ambiguity is lower for investors with higher financial literacy and better education. This is sensible, as better knowledge should help mitigate perceived ambiguity. For ambiguity aversion, 
we find that risk aversion can explain the highest share of its variation, while it is only weakly related to financial knowledge and education. This suggests that ambiguity aversion is a preference, not driven by lack of knowledge or low levels of sophistication.

Finally, to validate our ambiguity attitude measures, we explore how ambiguity aversion and perceived ambiguity relate to investors' actual investment choices. We find that investors who perceive less ambiguity about Bitcoin and a familiar individual stock are also more likely to invest in these two assets, as expected based on theory. Further, the crypto-currency investors in our sample are close to ambiguity neutral, suggesting that they are less sensitive to financial ambiguity in general.

Our results contribute to the empirical and theoretical literature on ambiguity attitudes. We are the first to measure ambiguity attitudes toward natural sources of ambiguity in a large-scale population survey. Related to our work, Abdellaoui, Baillon, Placido, and Wakker (2011), Baillon and Bleichrodt (2015), and Baillon et al. (2018b) measured ambiguity attitudes toward natural events, including stock index returns, in lab experiments with students. ${ }^{3}$ Baillon and Bleichrodt (2015) did not control for unknown probability beliefs, and as a result they could not draw definite conclusions about whether ambiguity attitudes differed toward domestic and foreign stock markets. Baillon et al. (2018b) did control for beliefs and measured ambiguity attitudes about the returns of one stock market index; nevertheless, they did not evaluate different sources of ambiguity. Baillon et al. (2018b) found correlations of about 0.8 between their repeated measurements, demonstrating the reliability of the new method. Using the same approach, $\mathrm{Li}$ (2017) measured ambiguity attitudes toward phrases in foreign languages to explore the relation between ambiguity attitudes and income among Chinese high school students. Li, Turmunk, and Wakker (2018) applied the method to demonstrate the importance of ambiguity aversion in a trust

\footnotetext{
${ }^{3}$ In addition, Abdellaoui et al. (2011) used complex measurements less suited for a general population survey, also requiring estimates of utility, probability weighting, and subjective beliefs.
} 
game conducted in a lab experiment. Using a different methodology, Brenner and Izhakian (2018) analyzed aggregate U.S. stock market data to measure ambiguity attitudes for a representative investor, whereas in the present paper we measure ambiguity attitudes at the individual level.

Our paper also contributes to the literature on portfolio choice under ambiguity (Dow and Werlang, 1992; Mukerji and Tallon, 2001; Cao et al., 2005; Epstein and Schneider, 2007; Easley and O'Hara, 2009; Bossaerts et al., 2010; Gollier, 2011; Mele and Sangiorgi, 2015; and Brenner and Izhakian, 2018). Consistent with modelling assumptions in Garlappi et al. (2007) and Peijnenburg (2018), we show that ambiguity preferences and perceived ambiguity levels are two distinct components of ambiguity attitudes. While we find substantial between-subject heterogeneity in ambiguity preferences, the within-subject measure can be described by one parameter. In contrast, perceived levels of ambiguity about different investment assets vary for the same individual, and hence these should be modelled separately for each asset.

In what follows, we first describe how we elicit and measure ambiguity attitudes. We next discuss our dataset, followed by an analysis of our empirical results on investors' ambiguity aversion levels as well as ambiguity beliefs. We then analyze how our measures relate to financial literacy and investment decisions. A short discussion concludes.

\section{Eliciting ambiguity attitudes}

\subsection{Measurement method}

We elicit ambiguity attitudes toward investments with the measurement method for natural events of Baillon et al. (2018b). The first source of ambiguity we evaluate is the return on the Amsterdam Exchange Index (AEX) over a 1-month period. ${ }^{4}$ The Baillon et al. (2018b) method

\footnotetext{
${ }^{4}$ The AEX is a stock market index composed of the shares of 25 companies traded on the Amsterdam stock market.
} 
divides the possible outcomes into three mutually exclusive and exhaustive events, denoted as $E_{1}, E_{2}$, and $E_{3}$. For the AEX index returns, these three events are defined as:

$$
\begin{array}{ll}
E_{1}=(-\infty,-4 \%] & : \text { the AEX index decreases by } 4 \% \text { or more } \\
E_{2}=(-4 \%,+4 \%) & : \text { the AEX index decreases or increases by less than } 4 \% \\
E_{3}=[+4 \%, \infty) & : \text { the AEX index increases by } 4 \% \text { or more. }
\end{array}
$$

For each event $E_{i}$ separately, we elicit the respondent's matching probability with a choice list. ${ }^{5}$ Figure 1 shows the choice list for event $E_{1}$ as an example. ${ }^{6}$ The matching probability $m_{i}$ is the known probability of winning $p=m_{i}$ at which the respondent is indifferent between Option A (winning $€ 15$ if Event $E_{1}$ happens) and Option B (winning $€ 15$ with known chance $p$ ). We approximate the matching probability by taking the average of the probabilities $p$ in the two rows that define the respondent's switching point from Option A to B. For example, in Figure 1 the matching probability is: $m_{1}=\frac{20 \%+30 \%}{2}=25 \%$.

\section{[Insert Figure 1 here]}

Apart from these three single events $\left(E_{1}, E_{2}\right.$, and $\left.E_{3}\right)$, the measurement method also elicits matching probabilities for the compliment of each event:

$$
\begin{array}{ll}
E_{23}=(-4 \%, \infty) & : \text { the AEX index does not decrease by } 4 \% \text { or more } \\
E_{13}=(-\infty,-4 \%] \cup[+4 \%, \infty) & : \text { the AEX index decreases or increases by } 4 \% \text { or more } \\
E_{12}=(-\infty,+4 \%) & : \text { the AEX index does not increase by } 4 \% \text { or more. }
\end{array}
$$

\footnotetext{
${ }^{5}$ For each row in the list, the respondent can choose between Option A and Option B. When the respondent chooses Option A, he wins $€ 15$ if the AEX index decreases by $4 \%$ or more in one month. When the respondent chooses Option $\mathrm{B}$, in one month he wins $€ 15$ with a known probability of $p$, with $p$ increasing down the rows of the choice list.

${ }^{6}$ If the respondent clicks on $\mathrm{B}$ in a particular row, all answers in previous rows are set to A, and answers in all subsequent rows to $\mathrm{B}$ (i.e., multiple switching between $\mathrm{A}$ and $\mathrm{B}$ was not allowed). Assuming the event $E_{i}$ has some positive probability between 0 and 1 , choosing $\mathrm{B}$ in the first row of the list is a dominated choice, as is preferring Option A in the last row. Both choices (all A, or all B) were allowed, to check for respondent errors.
} 
The matching probability for the composite event $E_{i j}=E_{i} \cup E_{j}$ is denoted by $m_{i j}$, with $i \neq j$. For example, Figure 2 shows the choice list for the composite event $E_{23}$, when the AEX index does not decrease by $4 \%$ or more.

\section{[Insert Figure 2 here]}

A key insight of the Baillon et al. (2018b) method is that, for an ambiguity neutral decisionmaker, the matching probabilities of an event and its complement add up to $1\left(m_{1}+m_{23}=1\right)$, but under ambiguity aversion, the sum is less than $1\left(m_{1}+m_{23}<1\right)$. For example, the choices in Figure 1 and 2 imply that $1-m_{1}-m_{23}=1-0.25-0.55=0.2$, indicating ambiguity aversion. Baillon et al. (2018b) define their ambiguity aversion index $b$, after averaging over the three events, as follows:

$$
b=1-\bar{m}_{c}-\bar{m}_{s},
$$

with $-1 \leq b \leq 1$. Here $\bar{m}_{s}=\left(m_{1}+m_{2}+m_{3}\right) / 3$ denotes the average single-event matching probability, and $\bar{m}_{c}=\left(m_{12}+m_{13}+m_{23}\right) / 3$ is the average composite-event matching probability. The decision-maker is ambiguity neutral when $b=0$, ambiguity averse for $b>0$, and ambiguity seeking for $b<0$. Averaging over three events and their complements makes the ambiguity aversion index more robust to measurement error.

Ambiguity attitudes in practice have a second component apart from ambiguity aversion, namely a tendency to treat all uncertain events as though they had a $50-50 \%$ chance, which is called ambiguity-generated sensitivity or a-insensitivity (Tversky and Fox, 1995, Abdellaoui et al., 2011). For unlikely events, a-insensitivity leads to overweighting and more ambiguity-seeking choices. Conceptually, a-insensitivity is similar to inverse-S probability weighting, the tendency to overweight events with small known probabilities. Empirical studies have shown that a-insensitivity is a typical feature of decision-making under ambiguity, more common even than 
ambiguity aversion itself (Trautmann and van de Kuilen 2015, Dimmock et al., 2016). Baillon et al. (2018b) define the following index used to measure a-insensitivity:

$$
a=3 \times\left(1 / 3-\left(\bar{m}_{c}-\bar{m}_{s}\right)\right),
$$

with $-2 \leq a \leq 4 .{ }^{7}$ For ambiguity neutral decision-makers, $a=0$, while $a>0$ denotes a-insensitivity, the typical finding in empirical studies. Negative values, $a<0$, indicate that the decision-maker is overly sensitive to changes in the likelihood of ambiguous events (i.e., tending to underweight unlikely events).

There are two key advantages of using the Baillon et al. (2018b) method. First, averaging over the three single events and their complements in the calculation of indexes $b$ and $a$ ensures that the unknown subjective probabilities drop out of the equation (see Section 2.2 and Baillon et al., 2018b). Hence we can measure ambiguity aversion regarding an asset without knowing the respondents' subjective probabilities $\left(P\left(E_{i}\right)\right)$ for the asset returns. This solves the important issue that, when observing a dislike of ambiguity, it is difficult to disentangle whether this is due to aversion to ambiguity or pessimistic subjective beliefs. Second, we also need not know the respondent's utility function (e.g., $U(15)$ ), as we use matching probabilities and a fixed price of $€ 15$ for both Options $A$ and $B$ on the choice lists. Using matching probabilities, we measure ambiguity aversion relative to risk aversion, because the alternative to the ambiguous choice is a risky choice, not a sure amount. This ensures that utility drops out of the equation as well (Dimmock et al., 2016).

Following the same procedure as described above for the AEX index, our survey module also elicited six matching probabilities each for three additional sources of financial ambiguity: a

\footnotetext{
${ }^{7}$ Baillon et al. (2018) note that monotonicity requires that the average matching probability of the composite events should exceed the average matching probability of the single events $\left(\bar{m}_{c} \geq \bar{m}_{s}\right)$, ensuring $a \leq 1$. In practice, respondents can make errors and violate monotonicity, leading to $a>1$.
} 
familiar company stock, a foreign stock index (MSCI World), and the crypto-currency Bitcoin. A more detailed description of the survey implementation follows in Section 2.3. We first provide a decision-making model to underpin the interpretation of indexes $b$ and $a$ as measures of ambiguity aversion and perceived ambiguity.

\subsection{A model for ambiguity aversion and perceived ambiguity}

In the context of the $\alpha$-MaxMin model, Dimmock, Kouwenberg, Mitchell, and Peijnenburg (2015) and Baillon et al. (2018a) show that index $b$ and $a$ can be interpreted, respectively, as ambiguity aversion and the perceived level of ambiguity. Here we summarize those results to provide intuition for the meaning of indexes $b$ and $a$, and to demonstrate that subjective beliefs are controlled for. Let $\mathcal{E}$ denote the set with all possible events. A probability measure $P$ is a function $P: \mathcal{E} \rightarrow \mathbb{R}$ that assigns probabilities between 0 and 1 to the events. ${ }^{8}$ Let $\mathcal{P}$ denote the set of all possible probability measures. A prospect $x$ is a function assigning outcomes to events, $x: \mathcal{E} \rightarrow \mathbb{R}$, giving monetary amount $x(E)$ if event $E$ occurs. For example, in Option A in Figure 1, event $E_{1}$ is a decrease of the $\mathrm{AEX}$ index by $4 \%$ or more, with outcome $x\left(E_{1}\right)=\$ 15$, while for the compliment event $x\left(E_{21}\right)=\$ 0$. Finally, we assume that the decision-maker has an increasing utility function $U: \mathbb{R} \rightarrow \mathbb{R}$ over outcomes.

Ambiguity occurs when the decision-maker does not know the exact probabilities of all events $E$ in $\mathcal{E}$. Multiple prior models assume that the decision-maker considers a convex set $\mathcal{C}$ of possible probability measures $P \in \mathcal{C}$. In the multiple prior model of Gilboa and Schmeidler (1989), the decision-maker uses the worst distribution in $\mathcal{C}$ when selecting the prospect $x$ with the highest expected utility: $\max _{x}\left(\min _{P \in \mathcal{C}} E_{P}[U(x)]\right)$. The MaxMin model implies that the decision-maker is

8 A probability measure has the following properties: $P(\varnothing)=0, P(S)=1, P(E) \leq P(F)$ for all events $E, F \in \mathcal{E}$ with $E \subseteq F$, and $P(E \cup F)=P(E)+P(F)-P(E \cap F)$. 
always strongly ambiguity averse. The $\alpha$-MaxMin model defined below provides more flexibility in modelling ambiguity preferences, including ambiguity seeking behavior (Hurwicz, 1951; Ghirardato, Maccheroni, and Marinacci, 2004):

$$
\max _{x}\left\{\alpha \min _{P \in \mathcal{C}} E_{P}[U(x)]+(1-\alpha) \max _{P \in \mathcal{C}} E_{P}[U(x)]\right\}, \text { with } \alpha \in[0,1] .
$$

In this model, $\alpha$ captures ambiguity preferences, while the set of prior distributions $\mathcal{C}$ reflects perceived ambiguity. The value $\alpha=1$ implies maximum ambiguity aversion (MaxMin), maximum ambiguity seeking occurs at $\alpha=0$, and $\alpha=1 / 2$ usually indicates ambiguity neutrality.

A tractable set of prior distributions for the $\alpha$-MaxMin model can be specified with the neo-additive model, axiomatized by Chateauneuf, Eichberger, and Grant (2007). The model assumes that the decision-maker has a reference probability distribution, $\pi$, an assessment of the unknown probabilities based on his subjective beliefs. However, the decision-maker does not fully trust his prior and has a degree of confidence of only $(1-\delta)$ in the reference probability $\pi$, with $\delta \in[0,1]$. He then considers the set $\mathcal{C}_{\delta}$ of all probability measures $P$ assigning at least probability $(1-\delta) \pi(E)$ to all events $E$ :

$$
\mathcal{C}_{\delta}=\{P \in \mathcal{P}: P(E) \geq(1-\delta) \pi(E), \text { for all } E \in \mathcal{E}\} \text {, with } \delta \in[0,1]
$$

The set of priors $\mathcal{C}_{\delta}$ imposes the following bounds on the probability measures $P \in \mathcal{C}_{\delta}: 0 \leq$ $(1-\delta) \pi(E) \leq P(E) \leq(1-\delta) \pi(E)+\delta \leq 1$, for all $E \in \mathcal{E}$. A higher value of $\delta$ means that the decision-maker perceives more ambiguity. In the special case $\delta=0$, with $100 \%$ confidence in the subjective probabilities, the model reduces to expected utility.

We now apply this model to the listed choices between Options A and B in Figure 1. The ambiguous Option A has two possible outcomes, $x\left(E_{1}\right)=\$ 15$ or $x\left(E_{23}\right)=\$ 0$, where event $E_{1}$ is a decrease of the AEX index by $4 \%$ or more (and $E_{23}$ is its complement). The utility function $U$ 
can be rescaled such that $U(0)=0$ and $U(15)>0$. The $\alpha$-MaxMin model with prior distribution set $\mathcal{C}_{\delta}$ then evaluates Option A as follows:

$$
\begin{aligned}
& \alpha \min _{p \in\left[(1-\delta) \pi_{1},(1-\delta) \pi_{1}+\delta\right]} p U(15)+(1-\alpha) \max _{p \in\left[(1-\delta) \pi_{1},(1-\delta) \pi_{1}+\delta\right]} p U(15) \\
& =\left((1-\delta) \pi_{1}+(1-\alpha) \delta\right) U(15)
\end{aligned}
$$

where $\pi_{1}=\pi\left(E_{1}\right)$ is the respondent's reference probability for event $E_{1}$.

Option B in the choice list offers a known probability $p$ of winning the $\$ 15$ prize and it is evaluated with expected utility $(\delta=0)$, giving: $E[U(x)]=p U(15)$. The matching probability $m_{1}$ is the known probability $p$ that makes the respondent indifferent between Option A and Option B, $\left((1-\delta) \pi_{1}+(1-\alpha) \delta\right) U(15)=m_{1} U(15)$, so the matching probability $m_{1}$ is:

$$
m_{1}=(1-\delta) \pi_{1}+(1-\alpha) \delta
$$

We see that utility $U$ has canceled out in the comparison between Option A and B, so we do not need to estimate the utility function (or risk aversion) in order to measure people's ambiguity attitudes. This is a major advantage of the elicitation method.

Our survey module also elicits a matching probability for the event $E_{23}$, i.e., the AEX index does not decrease by $4 \%$ or more (the complement of event $E_{1}$ ). Applying the same derivation, its matching probability is $m_{23}=(1-\delta) \pi_{23}+(1-\alpha) \delta$. We can now define a simplified ambiguity aversion index $b$ by measuring how much the sum of $m_{1}$ and $m_{23}$ deviates from 1 :

$$
b=1-\left(m_{1}+m_{23}\right)=1-(1-\delta)\left(\pi_{1}+\pi_{23}\right)-2(1-\alpha) \delta=2\left(\alpha-\frac{1}{2}\right) \delta .
$$

We see that the subjective probabilities $\pi_{1}$ and $\pi_{23}$ have dropped out in (7), as $\pi_{1}+\pi_{23}=$ 1. Hence, we can measure ambiguity aversion with index $b$ without having information about the decision-maker's subjective probabilities. This result also applies to the definition of index $b$ in 
(1), which is based on the average over three events. We also learn from Equation (7) that index $b$ is a rescaled version of $\alpha$, ranging from $-\delta$ to $\delta$ (Baillon et al., 2018b). ${ }^{9}$ Finally, index $b$ is positive for $\alpha>\frac{1}{2}$ (ambiguity aversion), negative for $\alpha<\frac{1}{2}$ (ambiguity seeking), and zero for $\alpha=\frac{1}{2}$ (ambiguity neutrality).

Similarly, for the a-insensitivity index $a$, we can derive the following expression in the $\alpha$-MaxMin model with prior set $\mathcal{C}_{\delta}$, when applied to the choice lists in Figures 1 and 2:

$$
\begin{aligned}
& \quad a=3 \times\left(\frac{1}{3}-\left(\bar{m}_{c}-\bar{m}_{s}\right)\right)=\left(1-(1-\delta)\left(\pi_{23}+\pi_{13}+\pi_{12}-\left(\pi_{1}+\pi_{2}+\pi_{3}\right)\right)\right. \\
& =\left(1-(1-\delta)\left(\left(1-\pi_{1}\right)+\left(1-\pi_{2}\right)+\left(1-\pi_{3}\right)-1\right)\right)=(1-(1-\delta))=\delta .
\end{aligned}
$$

Hence, index $a$ measures the perceived level of ambiguity $(\delta)$. As perceived ambiguity cannot be negative $(\delta \geq 0)$, this interpretation requires index $a$ to be non-negative $(a \geq 0)$. In our data, this is the case for the large majority of respondents $(98 \%){ }^{10}$

Figure 3 illustrates perceived ambiguity and ambiguity aversion. In Panel A, the left boxplot displays low perceived ambiguity (index $a=0.2$ ), and the right boxplot displays higher perceived ambiguity (index $a=0.4$ ). In both cases, the reference probability $\pi$ equals $50 \%$ and index $b=0.15$; however, the degree of confidence in this reference probability differs. In the left boxplot, the decision-maker believes that the probability ranges between $40 \%$ and $60 \%$, while in the right boxplot, the decision-maker has a wider set of beliefs (30-70\%). Panel B of Figure 3 illustrates ambiguity aversion, while keeping the reference probability $(\pi=50 \%)$ and the perceived level of ambiguity (index $a=0.4$ ) constant. In the right boxplot of Panel $\mathrm{B}$, the matching

\footnotetext{
${ }^{9}$ Alternatively, $2\left(\alpha-\frac{1}{2}\right)=b / a$ is a standardized measure of ambiguity aversion, ranging from -1 to 1 , that does not depend on how much ambiguity the person perceives. Estimating $\alpha$ from index $b$ and $a$ in practice entails numerical difficulties, as $b / a$ is not defined for values of $a$ close to zero, leading to outliers and missing observations.

${ }^{10}$ The average of index $a$ over the four sources is positive for 289 out of 295 respondents (98\%), see Section 3.
} 
probability ( $m=32.5 \%$; index $b=0.35)$ is lower compared to the left boxplot ( $m=42.5 \%$; index $b=0.15)$, showing that the former decision-maker is more ambiguity averse.

\section{[Insert Figure 3 here]}

Some readers may be concerned that the interpretation of index $a$ as perceived ambiguity is dependent on the particular prior distribution set $\mathcal{C}_{\delta}$ introduced by Chateauneuf et al. (2007). It is possible to use alternative prior sets such as the pessimistic one, $\mathcal{C}_{1}=[0,1]$, and the symmetric prior set $\mathcal{C}_{\text {sym }}$, with $\mathcal{C}_{\text {sym }}=\left\{p \in\left[\pi-\frac{1}{2} d, \pi+\frac{1}{2} d\right]\right\}$, for $d \geq 0$ and $d \leq \min \{2 \pi, 2(1-\pi)\}$. These alternative prior sets impose conditions on the matching probabilities that can be tested empirically. For example, it is easy to show that a symmetric prior set $\mathcal{C}_{\text {sym }}$ implies that index $a$ equals 0 , a condition that does not hold for nearly all survey respondents. Further, Dimmock et al. (2015) showed that the prior set $\mathcal{C}_{\delta}$ has strong empirical support in a large dataset on the ambiguity attitudes of the U.S. population, while $\mathcal{C}_{1}$ and $\mathcal{C}_{\text {sym }}$ were clearly rejected by the data. For this reason, from now on we interpret index $b$ as a measure of ambiguity aversion (preferences), and we interpret index $a$ as a measure of the perceived level of ambiguity (beliefs).

\subsection{Elicitation of ambiguity attitudes in the DHS panel}

Our DHS module for eliciting ambiguity attitudes started with one practice question in the same choice list format as Figure 1, where the uncertain event for Option A was whether the temperature in Amsterdam at 3 p.m. one month from now would be more than 20 degrees Celsius. After the practice question, a set of questions followed for each investment asset: the AEX index,

a familiar individual company stock, a foreign stock index (MSCI World), and a crypto-currency (Bitcoin). Six matching probabilities were measured for each investment separately, so that index $b$ (ambiguity aversion) and index $a$ (perceived level of ambiguity) can be estimated. The order of the four sets of questions was randomized, as was the order of the six events. Our final ambiguity 
aversion measures are labelled $b \_a e x, b \_s t o c k, b \_m s c i$, and $b \_b i t c o i n$ and our measures for the perceived level of ambiguity are labelled $a \_a e x, a \_s t o c k, a \_m s c i$, and $a \_b i t c o i n$. Furthermore, we define $b \_a v g$ as the average of the four $b$-indexes and $a \_a v g$ as the average of the four $a$-indexes.

Before beginning the questions about the individual stock, each respondent was first asked to name a familiar company stock, and subsequently that stock name was used in the six choice lists shown to the respondent. For those who indicated they did not know any familiar stock name, we used the company name Philips, a well-known Dutch consumer electronics brand. For the welldiversified AEX Index and the MSCI World Index, the event $E_{1}\left(E_{3}\right)$ represented a return of 4\% $(-4 \%)$ in one month. For the individual stock the percentage change was set to $8 \%$ and for Bitcoin to $30 \%$, to reflect the higher historical volatility of these investments. ${ }^{11}$

At the beginning of the survey, all subjects were told that one of their choices would be randomly selected and played for real money. We paid a total of $€ 2,758$ in real incentives to 199 of the 295 investors who completed the survey. ${ }^{12}$ The DHS was responsible for determining and making the incentive payments. As subjects in the DHS regularly receive payments for their participation, the involvement of the DHS should minimize subjects' potential concerns about the credibility of the incentives.

\footnotetext{
${ }^{11}$ The percentage change was set based on the approximate volatility of the asset $(15 \%$ for the AEX index and the MSCI World index, $40 \%$ for a typical individual stock, and 100\% for Bitcoin in February 2018), to ensure that the events $E_{1}, E_{2}$ and $E_{3}$ had non-negligible probabilities of occurring.

12 Real incentives were offered for both the ambiguity and the risk questions, with one randomly chosen question played for real money. The incentives were paid one month after the end of the survey, when the changes in the asset values were known.
} 


\section{Data and variables}

\subsection{DNB household panel}

Our purpose-built survey module to measure ambiguity attitudes was implemented in the DHS survey managed by CentERdata. ${ }^{13}$ The DHS consists of about 2,000 respondents that regularly answer Internet surveys. Households lacking internet access at the recruiting stage were provided with a set-top box for their television set (and with a TV if they had none) to limit selection bias. The DHS regularly fields modules to obtain information on income, work, assets, and liabilities. We merged those data with results from our custom-designed module on ambiguity and risk attitudes. The DHS has previously been used extensively to provide insight into other household financial decisions (e.g., Guiso, Sapienza, and Zingales, 2008; Van Rooij, Lusardi, and Alessie, 2011; Von Gaudecker, 2015; and Dimmock et al., 2016).

Our questionnaire was targeted at all DHS panel members who indicated that they invested in financial assets as of 31 December 2016, based on the October 2017 DHS survey of wealth and assets. Investors in the DHS are defined as individuals who own mutual funds (about $67 \%$ of the investors), individual company stocks $(50 \%)$, bonds $(10 \%)$, or options $(3 \%)$. Our survey module was fielded from 27 April-14 May 2018, yielding 295 complete and valid responses. ${ }^{14}$ Previously, in Section 2.1, we showed that the interpretation of index $a$ as a measure of perceived ambiguity requires $a \geq 0$. In our sample this restriction is satisfied for the large majority of the respondents, about 90\%, when considering each source separately (AEX index, familiar stock, foreign index, and Bitcoin). Our $a \_a v g$ measure, which eliminates some of the unobserved measurement errors, is strictly positive for all but six respondents whom we drop, yielding a final sample size of 289 investors.

\footnotetext{
13 Additional information is available on the survey entity at https://www.centerdata.nl/en/databank/dhs-data-access

14 Out of 391 DHS panel members who indicated that they invested in financial assets as of 31 December 2016,308 completed the survey questions, for a response rate of $79 \%$. Then we excluded 13 respondents who gave invalid responses when asked to name a familiar stock, leaving 295 valid responses.
} 
Table 1 displays summary statistics of the DHS investor sample. Education is an ordinal variable ranging from 1 to 6 , where 1 indicates primary education and 6 indicates a university degree. Household income is on average $€ 3,173$ per month. Household financial wealth consists of the sum of all current accounts, savings accounts, term deposits, cash value of insurance policies, bonds, mutual funds, stocks, options, and other financial assets such as loans to friends or family, all reported as of 31 December 2017 . Mean (median) wealth was $€ 142,620$ (€84,000). We also have variables for age, female, with partner, number of children living at home, employed, unemployed, and retired. Table 1 shows that the typical Dutch investor in financial markets was relatively old (61.3 years), male and well educated..$^{15}$

\section{[Insert Table 1 here]}

\subsection{Risk aversion}

The DHS module also included four separate choice lists to measure risk attitudes (two screenshots are provided in Online Appendix A). The first risk attitude choice list elicited a certainty equivalent for a known $50 \%$ chance of winning $€ 15$, based on a fair coin toss. The other three choice lists elicited a certainty equivalent for a chance of winning $€ 15$ of $33 \%, 17 \%$, and $83 \%$, respectively, using the throw of a die. Respondents could win real money for the risk questions, and the order of the risk and ambiguity question sets in the survey was randomized. Following Abdellaoui et al. (2011), we use index $b$ for risk as a measure of Risk Aversion and index $a$ for risk as a measure of Inverse-S probability weighting. These risk attitude measures have the advantage that they are conceptually related to index $b$ for ambiguity aversion and index $a$ for

\footnotetext{
${ }^{15}$ Our survey was also given to a random sample of 304 non-investors, with 225 complete responses (74\%). This noninvestor sample allows us to compare the ambiguity attitudes of investors and non-investors, which we do in Online Appendix $\mathrm{C}$ of the paper. For our main results we focus on investors, as our goal is to assess ambiguity attitudes of investors in financial markets, and to validate our measures by confirming that the ambiguity attitudes of investors are associated with their investment decisions.
} 
perceived ambiguity (Abdellaoui et al. 2011), while also having an axiomatic foundation in rankdependent utility. See Online Appendix B for more details about the risk attitude measures.

Table 1 shows that on average investors are risk averse (mean $>0$ ), but there is strong heterogeneity in risk preferences, as the standard deviation of Risk Aversion is high. Overall, two thirds of the investors are risk averse. Further, the Inverse-S probability weighting measure is positive for $86 \%$ of the investors, displaying a tendency to overweight small probabilities, which is in line with other studies (see, e.g., Fehr-Duda and Epper, 2011, and Dimmock et al., 2018).

\subsection{Financial literacy and asset ownership}

The DHS survey module also collected data on financial literacy and asset ownership. Financial literacy is one of our key independent variables, as we aim to assess whether this proxy for financial knowledge relates to ambiguity attitudes. To measure this, we use questions from Lusardi and Mitchell (2007) and Van Rooij et al. (2011) who devised both basic and more advanced financial literacy questions. An example of a basic literacy question is: "Suppose the interest on your savings account is $1 \%$ per year and the inflation is $2 \%$ per year. After 1 year, can

you buy more, exactly the same, or less than today with the money on the account? (1) More than today, (2) Exactly the same as today, (3) Less than today, (4) I do not know." An example of an advanced literacy question is: "Which of the following statements is correct? (1) If one invests in a mutual fund, one cannot withdraw the money in the first year, (2) Mutual funds can invest in several assets, for example invest in both stocks and bonds, (3) Mutual funds pay a guaranteed rate of return which depends on their past performance, (4) None of the above, (5) I do not know." (A complete listing of all the financial literacy questions is provided in Online Appendix B.) Our Basic Financial Literacy measure refers to the number of correct responses out of five basic questions, and the Advanced Financial Literacy measure refers to the number of correct responses 
out of seven advanced questions. Financial Literacy is the combined number of correct responses to both the basic and advanced questions. Table 1 shows that the average number of correct basic literacy questions was 4.5 out of five, and the average number of correct advanced literacy questions was six of seven.

We also validate our ambiguity measures by examining whether they relate to the financial assets owned by the investors. Our survey module asked the DHS panel members whether they currently invested in the familiar company stock they mentioned, and whether they invested in any crypto-currencies like Bitcoin. Invests in Familiar Stock is therefore an indicator variable equal to one if the investor currently held the familiar company stock he mentioned. About one-third of investors did hold the familiar stock (see Table 1). Invests in Crypto-Currencies is an indicator equal to one if the investor held any crypto-currencies, which was true for $2.4 \%$ of the DHS investors.

\section{Results for ambiguity attitudes}

In this section, we present results for ambiguity aversion and perceived ambiguity about the four investments.

\subsection{Ambiguity aversion}

Figure 4 shows the fraction of respondents who were ambiguity averse, ambiguity neutral, and ambiguity seeking, for the four sources of ambiguity: the familiar stock, the domestic stock market index (AEX), a foreign stock market index (MSCI World), and Bitcoin. To account for possible measurement error, we classify small values of index $b$ that are not significantly different from zero as ambiguity neutral. About two-thirds of the respondents are ambiguity averse, while one-third is ambiguity seeking, a pattern that is similar across the sources of financial ambiguity. 
Furthermore, ambiguity neutrality is rare, implying that very few investors' choices are consistent with the expected utility model. These findings are in line with earlier large-scale studies such as Dimmock et al. (2015), Dimmock, Kouwenberg, and Wakker (2016), and Kocher, Lahno, and Trautmann (2018), but the present paper is the first to confirm this result for economically relevant natural sources of uncertainty, instead of artificial ones like Ellsberg urns.

\section{[Insert Figure 4 here]}

Panel A of Table 2 shows descriptive statistics for the $b$-indexes, measuring ambiguity aversion. Investors on average appear to display somewhat higher ambiguity aversion toward the foreign stock index (0.21), compared to the domestic AEX index (0.17), the familiar individual stock (0.16), and Bitcoin (0.17). Yet these small differences pale in comparison to the strong heterogeneity in ambiguity aversion between investors, as indicated by the high standard deviation of the $b$-indexes (about 0.5 on average). We use Hotelling's $T$-squared statistic ${ }^{16}$ to test the hypothesis that the mean $b$-index is equal for the four investments; this cannot be rejected (see Table 2). This implies that the mean level of ambiguity aversion of our respondents does not depend on the source of financial uncertainty.

\section{[Insert Table 2 here]}

Figure 5 shows scatter plots of the relations between the ambiguity aversion measures for the four different financial sources. The correlations are all relatively strong, ranging between 0.63 and 0.74 . This implies that if an investor has relatively high ambiguity aversion toward one specific financial source (e.g., the AEX index), he also tends to display high ambiguity aversion toward the other three investments. A factor analysis shows that the first factor explains $77 \%$ of the crosssectional variation in the four ambiguity aversion measures, indicating that a single underlying

\footnotetext{
${ }^{16}$ Hotelling's $T$-squared statistic $\left(T^{2}\right)$ is a generalization of the paired samples $t$-test used in a multivariate setting with more than two related measurements.
} 
preference variable is driving all four $b$-indexes. Relatedly, Cronbach's alpha ${ }^{17}$ of the four ambiguity aversion measures is 0.90 (on a scale from 0 to 1 ), confirming that the $b$-index values for the four investments move together strongly. Overall, these results show that ambiguity aversion toward different investments is effectively driven by a single underlying preference variable.

\section{[Insert Figure 5 here]}

\subsection{Perceived ambiguity}

We now analyze the $a$-index values which measure the level of perceived ambiguity toward the four investments. Figure 6 shows that the a-index values are non-negative in 90 to $97 \%$ of the cases, depending on the source of ambiguity, confirming our interpretation of the measure as the perceived level of ambiguity which requires $a \geq 0 .{ }^{18}$ Panel B of Table 2 shows descriptive statistics for the $a$-indexes. On average, investors have a lower level of perceived ambiguity toward the familiar individual stock (0.71) than toward the foreign index $(0.80)$, the domestic stock index (0.84), and Bitcoin (0.86). Hotelling's $T$-squared test clearly rejects the null hypothesis that all means are equal ( $p$-value $=0.007)$. A follow-up analysis with paired $t$-tests shows that the mean $a$-index for the familiar stock is significantly lower than perceived ambiguity for the other three investments. Together, the results in Table 2 suggest that investors perceive rather high levels of ambiguity about all investments, although less for the familiar stock.

$$
\text { [Insert Figure } 6 \text { here] }
$$

\footnotetext{
${ }^{17}$ Cronbach's alpha is a measure of internal consistency, that is, how closely related a set of variables (items) are as a group, on a scale from 0 to 1 . Cronbach's alpha is a function of the number of test items and the average intercorrelation among the items, where higher inter-correlations lead to a higher Cronbach's alpha.

${ }^{18}$ As noted in Section 3.1, we exclude 6 respondents for whom the average $a$-index value over all four sources was negative $\left(a \_a v g<0\right)$. We still allow the individual $a$-indexes to take on some negative values, as this could be the result of unobserved measurement error.
} 
Figure 7 shows scatter plots of the relations between perceived ambiguity toward the four financial sources. Here the correlations between the $a$-indexes are low, ranging from 0.07 to 0.18 , in sharp contrast to the earlier results for the $b$-indexes. This implies that, for a given respondent, the perceived ambiguity toward different investments can vary substantially, showing only a weak relation. Furthermore, Cronbach's alpha for the $a$-indexes is low (0.34) and a factor analysis indicates that the first component accounts for only about $34 \%$ of the cross-sectional variation in the four measures. These findings support the view that individuals perceive different levels of ambiguity about different financial sources. Hence, the same investor can perceive relatively low ambiguity about a familiar stock while concurrently perceiving high ambiguity about another investment (e.g., the MSCI World index, or Bitcoin). This is intuitive, inasmuch as differences in perceived ambiguity are driven by the investor's familiarity and knowledge about each specific source.

\section{[Insert Figure 7 here]}

In sum, our results indicate that ambiguity aversion toward investments in general is driven by one underlying preference variable, while perceived levels of ambiguity differ depending on

the specific investment considered. This result supports theoretical work in finance that has modelled ambiguity attitudes with a single ambiguity preference parameter, but with different levels of perceived ambiguity depending on the investment source (e.g., Uppal and Wang, 2003; Garlappi et al., 2007; Boyle, Garlappi, Uppal, and Wang, 2012; and Peijnenburg, 2018).

\subsection{The relation between ambiguity aversion and perceived ambiguity}

Figure 8 investigates the relation between ambiguity preferences and perceived ambiguity, shown in the separate scatter plots for each source and for the composite average. The correlation between perceived ambiguity and ambiguity aversion about the AEX index is 0.13 , while for the 
familiar stock the correlation is 0.11 . The $a$-index and the $b$-index correlations for the MSCI index and Bitcoin are statistically insignificant. Overall, the correlations are low, suggesting that ambiguity aversion and perceived ambiguity are two separate aspects of ambiguity attitudes, as has been found previously for student samples (Abdellaoui et al., 2011; Baillon et al., 2018b) and for Ellsberg urns (Dimmock et al., 2015; Dimmock et al., 2016). We confirm that this result holds as well for natural sources of ambiguity related to investment, while controlling for unknown subjective beliefs. ${ }^{19}$

$$
\text { [Insert Figure } 8 \text { here] }
$$

\section{Ambiguity attitudes, financial knowledge, and investment choices}

Next we test how ambiguity attitudes correlate with financial knowledge and investment choices to provide insight into the variables associated with ambiguity aversion and perceived ambiguity. Furthermore, we aim to validate our ambiguity measures by testing the expected correlations with other variables, without implying causality.

\subsection{Ambiguity attitudes and financial knowledge}

A priori, we expect that investors with better financial knowledge and higher education would perceive less ambiguity about the distribution of investment returns. Instead, the relation between ambiguity aversion and financial knowledge (or education) is less clear. On the one hand, if ambiguity aversion is a rational response to high uncertainty that can protect people from

\footnotetext{
${ }^{19}$ The $\alpha$-MaxMin provides a possible explanation for our finding of no relation between ambiguity preferences and perceived ambiguity, based on Equation (7): it implies that the relation between index $a$ and $b$ is positive when $\alpha>$ $1 / 2$, but negative when $\alpha<1 / 2$. Intuitively, this means that when perceived ambiguity is high, both ambiguity averse and ambiguity seeking tendencies become stronger. Our data confirm this prediction in unreported results. For example, for the AEX index, the correlation between index $a$ and the absolute value of index $b$ is 0.27 . Similarly, the correlation between $a \_a v g$ and the absolute value of $b \_a v g$ is 0.37 . Hence ambiguity preferences and beliefs are related in a non-linear manner. As the effect size is moderate, this does not change our overall conclusion that ambiguity preferences and beliefs are two separate components of ambiguity attitudes.
} 
unexpected losses such as market crashes, financial knowledge (or education) is expected to be positively related to ambiguity aversion. On the other hand, if we consider all deviations from ambiguity neutrality to be irrational, then better knowledge would be associated with both lower ambiguity aversion and less ambiguity seeking. In sum, we expect that $a$-index is negatively related to financial knowledge and education, but for $b$-index the relationship is an empirical question.

Panel A of Table 3 reports the correlation of our ambiguity attitude measures with financial literacy and education. We find that ambiguity aversion is only weakly negatively related to both variables $(r=-0.09$ and -0.10 respectively). In contrast, more financially literate and highly educated investors on average perceive lower levels of ambiguity about sources of financial ambiguity $(r=-0.21$ and $r=-0.27)$. This is intuitive, as more investment knowledge should reduce the level of perceived ambiguity, index $a$.

Panel B of Table 3 presents these results in a multiple regression framework, where now we control for individual characteristics such as age, gender, employment, income, and financial assets. Column (1) shows the effect of these variables on ambiguity aversion, while Column (2) shows the effect on the perceived level of ambiguity. In Column (1), we observe that ambiguity aversion is not significantly related to financial literacy or education. In Column (2), both higher education and better financial literacy are associated with lower perceived ambiguity, as expected. Income also is negatively related to perceived ambiguity, possibly because income can proxy for education. Furthermore, people with higher incomes have relatively more to gain from learning about investments, thereby reducing their perceived level of ambiguity.

\section{[Insert Table 3 here]}

We note that Dimmock et al. (2015) found a positive relation between education and perceived ambiguity, but in that case the source of ambiguity was an artificial urn experiment. This 
highlights again that it is vital to measure perceived ambiguity for each source separately. Policies designed to increase financial literacy and the understanding of different investment opportunities could increase investments by reducing perceived ambiguity.

\subsection{Ambiguity and risk attitudes}

Table 3 also reports the correlation of ambiguity attitudes with the two risk preference metrics, Risk aversion and Inverse-S. We expect that ambiguity aversion will be positively related to risk aversion, as both measure preferences. Similarly, we expect that Inverse-S (overweighting of small probabilities) will be positively related to a-insensitivity (overweighting of unlikely events), and thus to perceived ambiguity. Table 3 confirms the positive empirical relation between risk aversion and ambiguity aversion $(r=0.49)$, consistent with Dimmock, et al. (2015), suggesting that ambiguity aversion is a component of preferences. Further, perceived ambiguity is positively related to Inverse-S $(r=0.29)$ and not to risk aversion, as expected. We note that the correlations between risk preferences and ambiguity attitudes are moderate ( 0.07 to 0.49$)$, confirming that risk and ambiguity attitudes are separate concepts, as suggested by Abdellaoui et al. (2011) and Dimmock et al. (2016). As a robustness check, in Online Appendix B we repeat the analysis with alternative non-parametric measures of risk attitudes; results are similar to those in Table 3.

\subsection{Ambiguity attitudes and investment choices}

Next we evaluate how ambiguity attitudes correlate with actual investment choices. As the direction of these effects could run either way, our goal is to validate our ambiguity attitude measures, rather than making a claim about causality. That is, investors may decide to buy an asset due to low perceived ambiguity and low ambiguity aversion, but then owning the asset could also alter their ambiguity attitudes (leading to lower perceived ambiguity and less aversion). 
First, we consider investment in the familiar individual stock. We expect that higher perceived ambiguity about the stock, denoted by $a_{-}$stock, is negatively related to investment in the stock (Uppal and Wang, 2003; and Boyle et al. 2012). Figure 9 shows that, among investors with low perceived ambiguity ( $a \_$stock below the median), over one third (36\%) invest in the familiar stock, versus only $24 \%$ of investors with high perceived ambiguity ( $a \_$stock above the median). It is more difficult to predict the relation between ambiguity aversion and investment in the familiar stock, as it depends on how much ambiguity the investors perceive about other available investment opportunities. ${ }^{20}$ Figure 9 suggests that investors with higher ambiguity aversion (b_avg above the median) are less likely to invest in the familiar stock (34\% versus $26 \%$ ), but this difference is not significant.

Columns (1) and (2) in Table 4 report logistic coefficients from models using Invests in the Familiar Stock as the dependent variable, regressed on $a \_s t o c k$ and $b \_a v g$. In Column (1), we find that perceived ambiguity is negatively related to investing the familiar stock: thus investors are less likely to hold an individual stock when they perceive more ambiguity about it. Yet the relation becomes insignificant when we control for other variables such as financial knowledge and education in Column (2). In both Columns (1) and (2), we find no significant relation between ambiguity aversion (b_avg) and investments in the familiar stock.

\section{[Insert Table 4 and Figure 9 here]}

Second, we consider investment in crypto-currencies such as Bitcoin. We expect that higher perceived ambiguity about Bitcoin, denoted by a_bitcoin, will be negatively related to investment in crypto-currency. Figure 9 shows that crypto-currency ownership is $4.7 \%$ in the group with low perceived ambiguity about Bitcoin (a_bitcoin below the median), while it is almost $0 \%$

\footnotetext{
${ }^{20}$ Our results are for investors only; the direction of the relation between ambiguity aversion and individual stock holdings is unclear as it depends on the relative ambiguity of all the assets considered by the investor. If, instead, we included both non-investors and investors in our sample, we would have expected a negative relation between ambiguity aversion and individual stock holdings (Bossaerts et al. 2010; and Peijnenburg, 2018).
} 
in the group with high perceived ambiguity (a_bitcoin above the median). The difference is similar for investors with high and low ambiguity aversion (b_avg above or below the median). Columns (3) and (4) of Table 4 provide estimated results for a logistic model with crypto-currency ownership as the dependent variable. We find a negative relation between $a \_b i t c o i n$ and $b \_a v g$ and investment in crypto-currencies, but $b \_a v g$ becomes insignificant after including controls such as financial knowledge. ${ }^{21}$ Overall, the negative correlations between perceived ambiguity and investment choices support the validity of our ambiguity measures.

\subsection{Robustness tests}

We have performed several robustness checks for our main results. First, we exclude 109 investors who violate the monotonicity condition ( $\left.a \_a v g>1\right)$, or who make more than three errors on any ambiguity question set. Online Appendix $\mathrm{C}$ shows that our results are robust to using this subsample of investors. In the reduced sample, ambiguity aversion is still driven by a single factor explaining $77 \%$ of the variation in the $b$-indexes, with Cronbach's alpha of 0.90 . Perceived ambiguity differs between sources, even for one individual: the first factor explains only $29 \%$ of the variation, with Cronbach's alpha of 0.14. In the multiple regression models, similar to Panel B of Table 3, risk aversion is the only driver of ambiguity aversion $\left(\mathrm{R}^{2}=23 \%\right)$. Further, when explaining perceived ambiguity, the betas of financial literacy, education, Inverse-S and income are now all significant at the $1 \%$ level, with higher effect sizes than before $\left(\mathrm{R}^{2}=35 \%\right)$.

Second, we explore the ambiguity attitudes from a representative sample of 225 noninvestors (see Online Appendix C), where we again find support for our main conclusions. Unsurprisingly, the perceived levels of ambiguity (index $a$ ) are higher for the non-investor sample, while ambiguity preferences (index $b$ ) on average are not different.

\footnotetext{
${ }^{21}$ The results in Column (4) come with a caveat as we include eight regressors while only seven investors hold bitcoin, potentially over-fitting the data (indicated by the high pseudo- $\mathrm{R}^{2}$ ).
} 


\section{Conclusion}

This paper is the first to estimate and compare ambiguity preferences and perceived ambiguity about real world assets in a large-scale survey of investors, while controlling for unknown subjective beliefs. We measure ambiguity attitudes in an incentivized survey module fielded in a large and nationally representative sample of Dutch investors. These ambiguity attitudes are elicited for four assets: a familiar company stock, a local stock index, a foreign stock index, and the crypto-currency Bitcoin. We find that ambiguity aversion toward these four investments can be described by a single preference variable, to the extent that a single factor can explain about $80 \%$ of the cross-sectional variation in the four measures. By contrast, perceived ambiguity can differ substantially for the same individual depending on the source and cannot be readily summarized by one variable.

We also explore the relation between individual characteristics and ambiguity attitudes. In our large-scale survey, we find that perceived ambiguity is mitigated by financial literacy and education, while ambiguity aversion is largely unrelated to both. We also show that ambiguity aversion about investments is positively correlated with risk aversion, suggesting it is a preference component. We validate our measures by providing evidence of a relation between ambiguity attitudes and investing in a familiar stock, as well as Bitcoin.

Our findings have implications for theoretical and empirical work in finance, suggesting that ambiguity aversion can be modelled with a single preference parameter, whereas perceived ambiguity must be measured separately for each investment. Furthermore, our results suggest that policies aimed at improving peoples' financial literacy and knowledge of financial markets can help stimulate equity market participation and reduce inequality, as these reduce peoples' perceived levels of ambiguity about financial assets. Further, policies aiming to reduce perceived 
ambiguity, the cognitive component, appear to be a more promising way to influence household portfolio choices than policies targeting ambiguity aversion, the preference component.

\section{References}

Abdellaoui, M., Baillon, A., Placido, L., \& Wakker, P. P. (2011). The rich domain of uncertainty: Source functions and their experimental implementation. American Economic Review, 101(2), 695-723.

Abdellaoui, M., Klibanoff, P., \& Placido, L. (2015). Experiments on compound risk in relation to simple risk and to ambiguity. Management Science, 61(6), 1306-1322.

Baillon, A., \& Bleichrodt, H. (2015). Testing ambiguity models through the measurement of probabilities for gains and losses. American Economic Journal: Microeconomics, 7(2), 77100.

Baillon, A., Bleichrodt, H., Keskin, U., l'Haridon, O., \& Li, C. (2018a). The effect of learning on ambiguity attitudes. Management Science, 64(5), 2181-2198.

Baillon, A., Huang, Z., Selim, A., \& Wakker, P. P. (2018b). Measuring ambiguity attitudes for all (natural) events. Econometrica, 86(5), 1839-1858.

Bianchi, M., \& Tallon, J. M. (2018). Ambiguity preferences and portfolio choices: Evidence from the field. Management Science. Forthcoming.

Bossaerts, P., Ghirardato, P., Guarnaschelli, S., \& Zame, W. R. (2010). Ambiguity in asset markets: Theory and experiment. Review of Financial Studies, 23(4), 1325-1359.

Boyle, P., Garlappi, L., Uppal, R., \& Wang, T. (2012). Keynes meets Markowitz: The trade-off between familiarity and diversification. Management Science, 58(2), 253-272.

Brenner, M., \& Izhakian, Y. (2018). Asset pricing and ambiguity: Empirical evidence. Journal of Financial Economics, 130(3), 503-531. 
Cao, H., Wang, T., \& Zhang, H. (2005). Model Uncertainty, Limited Market Participation, and Asset Prices. Review of Financial Studies, 18(4), 1219-1251.

Chateauneuf, A., Eichberger, J., \& Grant, S. (2007). Choice under uncertainty with the best and worst in mind: Neo-additive capacities. Journal of Economic Theory, 137(1), 538-567.

Dimmock, S. G., Kouwenberg, R., \& Wakker, P. P. (2016). Ambiguity attitudes in a large representative sample. Management Science, 62(5), 1363-1380.

Dimmock, S. G., Kouwenberg, R., Mitchell, O. S., \& Peijnenburg, K. (2015). Estimating ambiguity preferences and perceptions in multiple prior models: Evidence from the field. Journal of Risk and Uncertainty, 51(3), 219-244.

Dimmock, S. G., Kouwenberg, R., Mitchell, O. S., \& Peijnenburg, K. (2016). Ambiguity aversion and household portfolio choice puzzles: Empirical evidence. Journal of Financial Economics, 119(3), 559-577.

Dimmock, S. G., Kouwenberg, R., Mitchell, O. S., \& Peijnenburg, K. (2018). Household portfolio underdiversification and probability weighting: Evidence from the field. Working paper, National Bureau of Economic Research (No. w24928).

Dow, J., \& da Costa Werlang, S. R. (1992). Uncertainty aversion, risk aversion, and the optimal choice of portfolio. Econometrica, 197-204.

Easley, D., \& O’Hara, M. (2009). Ambiguity and nonparticipation: The role of regulation. Review of Financial Studies, 22(5), 1817-1843.

Epstein, L. G., \& Schneider, M. (2007). Learning under ambiguity. Review of Economic Studies, 74(4), 1275-1303.

Epstein, L. G., \& Schneider, M. (2010). Ambiguity and asset markets. Annual Review of Financial Economics, 2(1), 315-346 
Fehr-Duda, H., \& Epper, T. (2011). Probability and risk: Foundations and economic implications of probability-dependent risk preferences. Annual Review of Economics, 4(1), 567-593

Garlappi, L., Uppal, R., \& Wang, T. (2007). Portfolio selection with parameter and model uncertainty: A multi-prior approach. Review of Financial Studies, 20(1), 41-81.

Ghirardato, P., Maccheroni, F., \& Marinacci, M. (2004). Differentiating ambiguity and ambiguity attitude. Journal of Economic Theory, 118(2), 133-173.

Gilboa, I., \& Schmeidler, D. (1989). Maxmin expected utility with non-unique prior. Journal of Mathematical Economics, 18(2), 141-153.

Gollier, C. (2011). Portfolio choices and asset prices: The comparative statics of ambiguity aversion. Review of Economic Studies, 78(4), 1329-1344.

Guiso, L., Sapienza, P., \& Zingales, L. (2008). Trusting the stock market. Journal of Finance, 63(6), 2557-2600.

Hurwicz, L. (1951). Some specification problems and applications to econometric models. Econometrica, 19(3), 343-344.

Kocher, M. G., Lahno, A. M., \& Trautmann, S. T. (2018). Ambiguity aversion is not universal. European Economic Review, 101(1), 268-283.

Li, C. (2017). Are the poor worse at dealing with ambiguity? Journal of Risk and Uncertainty, 54(3), 239-268.

Li, C., Turmunkh, U., \& Wakker, P. P. (2018). Trust as a decision under ambiguity. Experimental Economics. Forthcoming.

Lusardi, A., \& Mitchell, O.S. (2007). Baby boomers' retirement security: The role of planning, financial literacy and housing wealth. Journal of Monetary Economics 54(1), 205-224.

Mele, A., \& Sangiorgi, F. (2015). Uncertainty, information acquisition, and price swings in asset markets. Review of Economic Studies, 82(4), 1533-1567. 
Mukerji, S., \& Tallon, J. M. (2001). Ambiguity aversion and incompleteness of financial markets. Review of Economic Studies, 68(4), 883-904.

Peijnenburg, K. (2018). Life-cycle asset allocation with ambiguity aversion and learning. Journal of Financial and Quantitative Analysis, 53(5), 1963-1994.

Trautmann, S. T., \& Van De Kuilen, G. (2015). Ambiguity attitudes. In G. Keren \& G. Wu (Eds.), The Wiley Blackwell Handbook of Judgment and Decision Making (pp. 89-116). Oxford, UK: Wiley-Blackwell.

Tversky, A., \& Fox, C. R. (1995). Weighing risk and uncertainty. Psychological Review, 102(2), 269-283.

Uppal, R., \& Wang, T. (2003). Model misspecification and underdiversification. Journal of Finance, 58(6), 2465-2486.

Van Rooij, M., Lusardi, A., \& Alessie, R. (2011). Financial literacy and stock market participation. Journal of Financial Economics, 101(2), 449-472.

Von Gaudecker, H. M. (2015). How does household portfolio diversification vary with financial literacy and financial advice? Journal of Finance, 70(2), 489-507. 


\section{Table 1: Descriptive Statistics of the DHS Investor Dataset}

This table reports summary statistics of the socio-demographics, risk preferences, financial literacy and asset ownership of investors in the DHS panel. Sample size is $n=289$ investors, who owned bonds, mutual funds, individual stocks, or stock options, as of 31 December 2016. Family income (monthly, after tax) and household financial wealth are measured in euros. The reference category for employment status is either unemployed or not actively seeking work (12\%). Risk aversion, investment in the familiar stock, and investment in crypto-currencies are measured in our ambiguity survey module (see text).

\begin{tabular}{lccccc}
\hline & Mean & Median & St dev & Min & Max \\
\hline Socio-demographics & & & & & \\
Age & 61.29 & 63 & 14.40 & 21 & 93 \\
Female & 0.25 & 0 & 0.43 & 0 & 1 \\
Single & 0.29 & 0 & 0.45 & 0 & 1 \\
Number of kids & 0.38 & 0 & 0.82 & 0 & 3 \\
Education & 4.29 & 5 & 1.42 & 1 & 6 \\
Employed & 0.45 & 0 & 0.50 & 0 & 1 \\
Retired & 0.43 & 0 & 0.50 & 0 & 1 \\
Family Income & 3,173 & 2,900 & 1,663 & 0 & 11,975 \\
Financial Wealth & 142,620 & 84,000 & 247,117 & 0 & $3,260,448$ \\
& & & & & \\
Risk Preferences & & & & & \\
Risk Aversion & 0.12 & 0.08 & 0.47 & -1.00 & 1.00 \\
Indicator for Risk Aversion $>0$ & 0.65 & 1.00 & 0.48 & 0.00 & 1.00 \\
Inverse-S & 0.59 & 0.59 & 0.52 & -0.73 & 1.83 \\
Indicator for Inverse-S $>0$ & 0.86 & 1.00 & 0.35 & 0.00 & 1.00 \\
Financial Literary & & & & & \\
Basic & & & & & \\
Advanced & 4.54 & 5 & 0.67 & 2 & 5 \\
Total & 6.00 & 6 & 1.41 & 0 & 7 \\
Investment Assets & 10.54 & 11 & 1.71 & 3 & 12 \\
Invests in Familiar Stock & & & & & \\
Invests in Crypto-Currencies & 0.024 & 0 & 0.15 & 0 & 1 \\
\hline
\end{tabular}




\section{Table 2: Descriptive Statistics for Ambiguity Measures}

Panel A shows summary statistics for ambiguity attitudes regarding the local stock market index $\left(b \_a e x\right)$, a familiar company stock ( $\left.b \_s t o c k\right)$, the MSCI World stock index $\left(b \_m s c i\right)$ and Bitcoin $\left(b \_b i t c o i n\right)$, as well as the average of the four b-indexes $\left(b_{-} a v g\right)$. Positive values of the $b$-index denote ambiguity aversion, and negative values indicate ambiguity seeking. Panel B shows summary statistics for the perceived ambiguity indexes regarding the local stock market index ( $\left.a \_a e x\right)$, a familiar company stock ( $a$ stock), the MSCI World stock index $\left(a \_m s c i\right)$ and Bitcoin ( $a \_$bitcoin), as well as the average of the four $a$-indexes $\left(a \_a v g\right)$. Positive values of the $a$-index denote perceived ambiguity. The sample consists of $n=289$ investors. In Panel $\overline{\mathrm{A}}$, Hotelling's $T^{2}$ tests the null hypothesis that the means of the four ambiguity attitude measures are equal for $b \_a e x, b \_s t o c k, b \_m s c i$ and $b \_$bitcoin. In Panel B, Hotelling's $T^{2}$ tests whether the means of the four perceived ambiguity measures are equal for $a \_\bar{a} e x, a \_s t o c k, a \_m s c i$ and $a \_b i t c o i n$.

Panel A: Ambiguity Aversion

\begin{tabular}{lccccc} 
& & & & \\
& Mean & Median & St dev & Min & Max \\
\hline b_aex & 0.17 & 0.10 & 0.49 & -1.00 & 1.00 \\
b_stock & 0.16 & 0.10 & 0.48 & -1.00 & 1.00 \\
b_msci & 0.21 & 0.16 & 0.48 & -1.00 & 1.00 \\
b_bitcoin & 0.17 & 0.13 & 0.52 & -1.00 & 1.00 \\
b_avg & 0.18 & 0.15 & 0.43 & -1.00 & 1.00 \\
Test of equal means: Hotelling's $T^{2}=7.51, p=0.0608$ & & \\
\hline
\end{tabular}

Panel B: Perceived Ambiguity

\begin{tabular}{lccccc} 
& Mean & Median & St dev & Min & Max \\
\hline a_aex & 0.84 & 1.00 & 0.52 & -0.70 & 2.99 \\
a_stock & 0.71 & 0.86 & 0.62 & -1.45 & 2.90 \\
a_msci & 0.80 & 0.92 & 0.49 & -1.00 & 2.80 \\
a_bitcoin & 0.86 & 1.00 & 0.48 & -1.02 & 2.61 \\
\multicolumn{1}{l}{ a_avg } & 0.80 & 0.88 & 0.31 & 0.02 & 1.73 \\
Test of equal means: Hotelling's $T^{2}=12.33, p=0.0073$ & \\
\hline
\end{tabular}




\section{Table 3: Factors Associated with Ambiguity Attitudes}

Panel A shows correlations of ambiguity aversion ( $\left.b \_a v g\right)$ and perceived ambiguity ( $\left.a \_a v g\right)$ with financial literacy, education, risk aversion, and Inverse-S probability weighting. Panel B shows standardized beta coefficients from regression models of ambiguity aversion and perceived ambiguity regarding financial sources. In Column (1), the dependent variable is $b \_a v g$, the index of ambiguity aversion averaged over the four financial sources (aex, stock, msci and bitcoin). In Column (2), the dependent variable is $a \_a v g$, the index of perceived ambiguity averaged over the four financial sources (aex, stock, msci and bitcoin). In Panel B, the controls are financial literacy (total score), education, risk aversion, Inverse-S probability weighting, age, gender, single, an indicator for employment, the logarithm of the number of children living at home, family income, and household financial wealth, plus a control for missing wealth. The sample consists of $n=289$ investors. ${ }^{*},{ }^{* *},{ }^{* * *}$ denote significant coefficients at the $10 \%, 5 \%$ and $1 \%$ level.

\section{Panel A: Correlations with Financial Literacy, Education and Risk Attitudes}

\begin{tabular}{lcc}
\hline & $(1)$ & $(2)$ \\
& Ambiguity & Perceived \\
& Aversion & Ambiguity \\
& $b a v g$ & $a$ avg \\
\hline Financial Literacy & -0.09 & $-0.21^{* * *}$ \\
Education & $-0.10^{*}$ & $-0.27^{* * *}$ \\
Risk Aversion & $0.49^{* * *}$ & 0.09 \\
Inverse-S & 0.07 & $0.29^{* * *}$ \\
\hline
\end{tabular}

Panel B: Multiple Regression Models

\begin{tabular}{lcc}
\hline & $(1)$ & $(2)$ \\
& $\begin{array}{c}\text { Ambiguity } \\
\text { Aversion } \\
\text { b_avg }\end{array}$ & $\begin{array}{c}\text { Perceived } \\
\text { Ambiguity } \\
\text { a_avg }\end{array}$ \\
\hline Financial Literacy & -0.058 & $-0.123^{* *}$ \\
Education & -0.058 & $-0.201^{* * *}$ \\
Risk Aversion & $0.504^{* * *}$ & 0.006 \\
Inverse-S & $-0.109^{*}$ & $0.220^{* * *}$ \\
Age & $0.117^{*}$ & 0.094 \\
Female & 0.055 & -0.050 \\
Single & -0.086 & -0.062 \\
Employed & -0.052 & -0.022 \\
Number of kids $(\log )$ & 0.051 & 0.016 \\
Family Income $(\log )$ & 0.053 & $-0.085^{*}$ \\
Financial Wealth $(\log )$ & -0.061 & 0.065 \\
\hline $\mathrm{R}^{2}$ & 0.302 & 0.180 \\
$\mathrm{~N}$ & 289 & 289 \\
\hline
\end{tabular}




\section{Table 4: Investment in Familiar Stock and Crypto-Currency}

This table reports estimated results for investing in a familiar stock (columns 1 and 2) and investing in crypto-currency (columns 3 and 4). The numbers displayed are percent changes in the odds ratio $(\exp (\beta)-1)$ of investing in the asset based on estimated coefficients $(\beta)$ from a logistic regression model. In Columns (1) and (2), the dependent variable is 1 if the respondent invests in the familiar individual stock and 0 otherwise. In Columns (3) and (4), the dependent variable is 1 if the respondent invests in crypto-currency and 0 otherwise. Independent variables include $b \_a v g$, the overall index of ambiguity aversion averaged over the four financial sources (aex, stock, msci and bitcoin), as well as perceived ambiguity about the familiar stock ( $a$ stock) and perceived ambiguity about Bitcoin ( $a$ _bitcoin). In Column (2), a full set of control variables is included (as in Table 3). Since only few people invest in crypto-currency, Column (4) omits all discrete controls such as gender and education to avoid problems with complete separation (when a discrete explanatory variable completely separates the dependent variable). The sample consists of $n=289$ investors. ${ }^{*},{ }^{* *},{ }^{* * *}$ denote significant coefficients at the $10 \%, 5 \%$ and $1 \%$ level.

\begin{tabular}{|c|c|c|c|c|}
\hline & \multicolumn{2}{|c|}{$\begin{array}{l}\text { Investment in } \\
\text { Familiar Stock }\end{array}$} & \multicolumn{2}{|c|}{$\begin{array}{c}\text { Investment in } \\
\text { Crypto-Currencies }\end{array}$} \\
\hline & (1) & (2) & (3) & (4) \\
\hline a_stock & $-0.365^{* *}$ & -0.262 & & \\
\hline a_bitcoin & & & $-0.597^{* *}$ & -0.656 \\
\hline$b$ avg & -0.329 & -0.450 & $-0.676^{* * *}$ & -0.632 \\
\hline Financial Literacy & & $0.243^{*}$ & & -0.009 \\
\hline Education & & 0.094 & & \\
\hline Risk Aversion & & 0.775 & & 0.007 \\
\hline Inverse-S & & -0.288 & & 0.102 \\
\hline Age & & 0.024 & & $-0.148^{* * *}$ \\
\hline Female & & -0.386 & & \\
\hline Single & & 0.017 & & \\
\hline Employed & & $1.851^{* * *}$ & & \\
\hline Number of kids $(\log )$ & & 0.112 & & \\
\hline Family Income (log) & & 0.101 & & -0.181 \\
\hline Financial Wealth (log) & & 0.013 & & 0.248 \\
\hline Pseudo $\mathrm{R}^{2}$ & 0.020 & 0.096 & 0.043 & 0.410 \\
\hline $\mathrm{N}$ & 289 & 289 & 289 & 289 \\
\hline
\end{tabular}




\section{Figure 1: First Choice List for Eliciting Ambiguity Attitudes about the AEX Index}

The following questions will be about the value of the AEX index: the Amsterdam Exchange index, a stock market index composed of the shares of 25 Dutch companies that trade on the stock market in Amsterdam.

For each of the 15 rows below, please choose whether you prefer Option A or Option B.

Option A: pays off $€ 15$ if the AEX decreases by $4 \%$ or more in one month time compared to what the index value is today.

Option B: pays off $€ 15$ with a given chance, with the chance increasing down the rows of the table. For example, in row 1 the chance is $0 \%$, in row 2 the chance is $2.5 \%$, etc., until in row 15 the chance is $100 \%$.

Note: any amount you win will be paid after one month, both for Option A and Option B.

\begin{tabular}{|c|c|c|c|}
\hline $\begin{array}{l}\text { Option A } \\
\text { You win } € 15 \text { if the AEX decreases by } \\
4 \% \text { or more in one month time } \\
\text { compared to what the index value is } \\
\text { today (and nothing otherwise) }\end{array}$ & A & $\mathrm{B}$ & $\begin{array}{l}\text { Option B } \\
\text { You win } € 15 \text { in one month time } \\
\text { with the following chance } \\
\text { (and nothing otherwise) }\end{array}$ \\
\hline \multirow{5}{*}{$\begin{array}{c}\text { A: Win } € 15 \text { if the AEX decreases by } \\
4 \% \text { or more in } 1 \text { month time }\end{array}$} & $\mathrm{X}$ & & B: Win $€ 15$ with chance of $0 \%$ \\
\hline & $\mathrm{X}$ & & B: Win $€ 15$ with chance of $2.5 \%$ \\
\hline & $\mathrm{X}$ & & B: Win $€ 15$ with chance of $5 \%$ \\
\hline & $\mathrm{X}$ & & B: Win $€ 15$ with chance of $10 \%$ \\
\hline & $\mathrm{X}$ & & B: Win $€ 15$ with chance of $20 \%$ \\
\hline \multirow{2}{*}{$-4 \% \quad 0 \% \quad+4 \%$} & & $\mathrm{X}$ & B: Win $€ 15$ with chance of $30 \%$ \\
\hline & & $\mathrm{X}$ & B: Win $€ 15$ with chance of $40 \%$ \\
\hline & & $\mathrm{X}$ & B: Win $€ 15$ with chance of $50 \%$ \\
\hline \multirow{7}{*}{$€ 15 \quad € 0$} & & $\mathrm{X}$ & B: Win $€ 15$ with chance of $60 \%$ \\
\hline & & $\mathrm{X}$ & B: Win $€ 15$ with chance of $70 \%$ \\
\hline & & $\mathrm{X}$ & B: Win $€ 15$ with chance of $80 \%$ \\
\hline & & $\mathrm{X}$ & B: Win $€ 15$ with chance of $90 \%$ \\
\hline & & $\mathrm{X}$ & B: Win $€ 15$ with chance of $95 \%$ \\
\hline & & $\mathrm{X}$ & B: Win $€ 15$ with chance of $97.5 \%$ \\
\hline & & $\mathrm{X}$ & B: Win $€ 15$ with chance of $100 \%$ \\
\hline
\end{tabular}


Figure 2: Second Choice List for Eliciting Ambiguity Attitudes about the AEX Index

For each of the 15 rows below, please choose whether you prefer Option A or Option B.

Option A: pays off $€ 15$ if the AEX does not decrease by $4 \%$ or more in one month time compared to what the index value is today.

Option B: pays off $€ 15$ with a given chance, with the chance increasing down the rows of the table. For example, in row 1 the chance is $0 \%$, in row 2 the chance is $2.5 \%$, etc., until in row 15 the chance is $100 \%$.

Note: any amount you win will be paid after one month, both for Option A and Option B.

\begin{tabular}{|c|c|c|c|}
\hline $\begin{array}{l}\text { Option A } \\
\text { You win } € 15 \text { if the AEX does } \\
\text { not decrease by } 4 \% \text { or more in one } \\
\text { month time compared to what the index } \\
\text { value is today (and nothing otherwise) }\end{array}$ & A & B & $\begin{array}{l}\text { Option B } \\
\text { You win } € 15 \text { in one month time } \\
\text { with the following chance } \\
\text { (and nothing otherwise) }\end{array}$ \\
\hline \multirow{5}{*}{$\begin{array}{l}\mathrm{A}: \text { Win } € 15 \text { if the } \mathrm{AEX} \text { does } \\
\text { not decrease by } 4 \% \text { or more } \\
\text { in } 1 \text { month time }\end{array}$} & $\mathrm{X}$ & & B: Win $€ 15$ with chance of $0 \%$ \\
\hline & $\mathrm{X}$ & & B: Win $€ 15$ with chance of $2.5 \%$ \\
\hline & $\mathrm{X}$ & & B: Win $€ 15$ with chance of $5 \%$ \\
\hline & $\mathrm{X}$ & & B: Win $€ 15$ with chance of $10 \%$ \\
\hline & $\mathrm{X}$ & & B: Win $€ 15$ with chance of $20 \%$ \\
\hline \multirow{3}{*}{$-4 \% \quad 0 \% \quad+4 \%$} & $\mathrm{X}$ & & B: Win $€ 15$ with chance of $30 \%$ \\
\hline & $\mathrm{X}$ & & B: Win $€ 15$ with chance of $40 \%$ \\
\hline & $\mathrm{X}$ & & B: Win $€ 15$ with chance of $50 \%$ \\
\hline \multirow{7}{*}{$€ 0 \quad € 15$} & & $\mathrm{X}$ & B: Win $€ 15$ with chance of $60 \%$ \\
\hline & & $\mathrm{X}$ & B: Win $€ 15$ with chance of $70 \%$ \\
\hline & & $\mathrm{X}$ & B: Win $€ 15$ with chance of $80 \%$ \\
\hline & & $\mathrm{X}$ & B: Win $€ 15$ with chance of $90 \%$ \\
\hline & & $\mathrm{X}$ & B: Win $€ 15$ with chance of $95 \%$ \\
\hline & & $\mathrm{X}$ & B: Win $€ 15$ with chance of $97.5 \%$ \\
\hline & & $\mathrm{X}$ & B: Win $€ 15$ with chance of $100 \%$ \\
\hline
\end{tabular}




\section{Figure 3: Perceived Ambiguity and Ambiguity Aversion}

The two box plots in Panel A illustrate low and high perceived ambiguity. In all plots, the reference probability is $\pi=$ $50 \%$. In the left plot in Panel A, perceived ambiguity is relatively low (index $a=0.2$ ), with the set of prior probabilities ranging from 40 to $60 \%$. In the right plot in Panel A, perceived ambiguity is higher (index $a=0.4$ ), and the set of prior probabilities ranges from 30 to $70 \%$. In Panel B, the two box plots illustrate low and high ambiguity aversion, while perceived ambiguity is constant (index $a=0.4$ ). In the left plot in Panel $\mathrm{B}$, the matching probability $m$ is $42.5 \%$ (less than $50 \%$, indicating ambiguity aversion) and index $b$ is 0.15 . In the right plot in Panel $\mathrm{B}$, the matching probability $m$ is $32.5 \%$ and index $b$ is 0.35 , displaying stronger ambiguity aversion than in the left plot.

\section{Panel A Low and High Perceived Ambiguity}

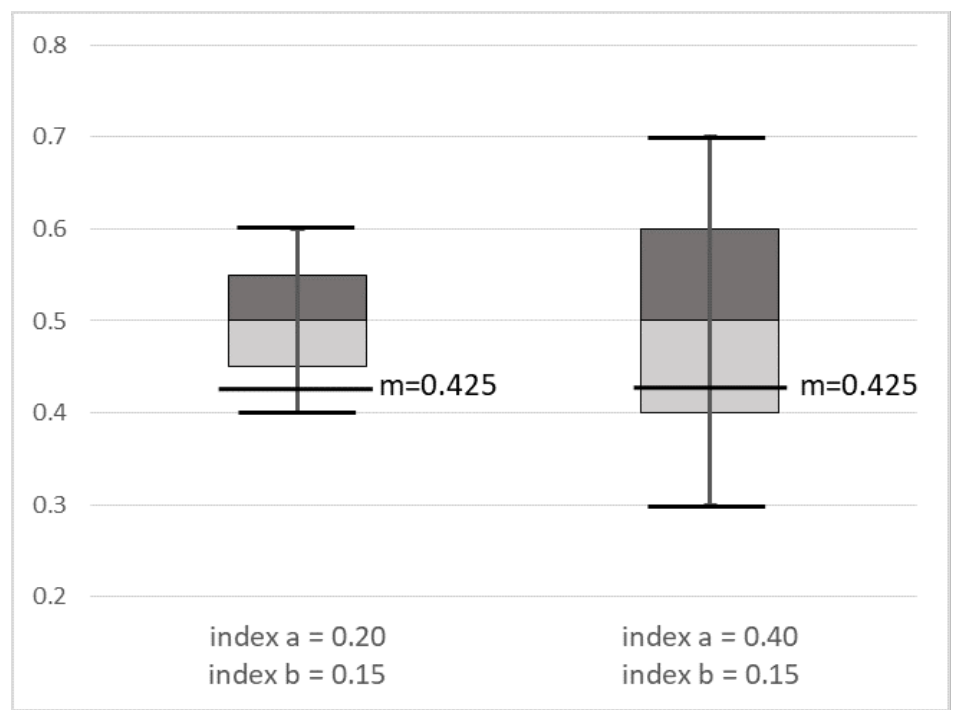

Panel B Low and High Ambiguity Aversion

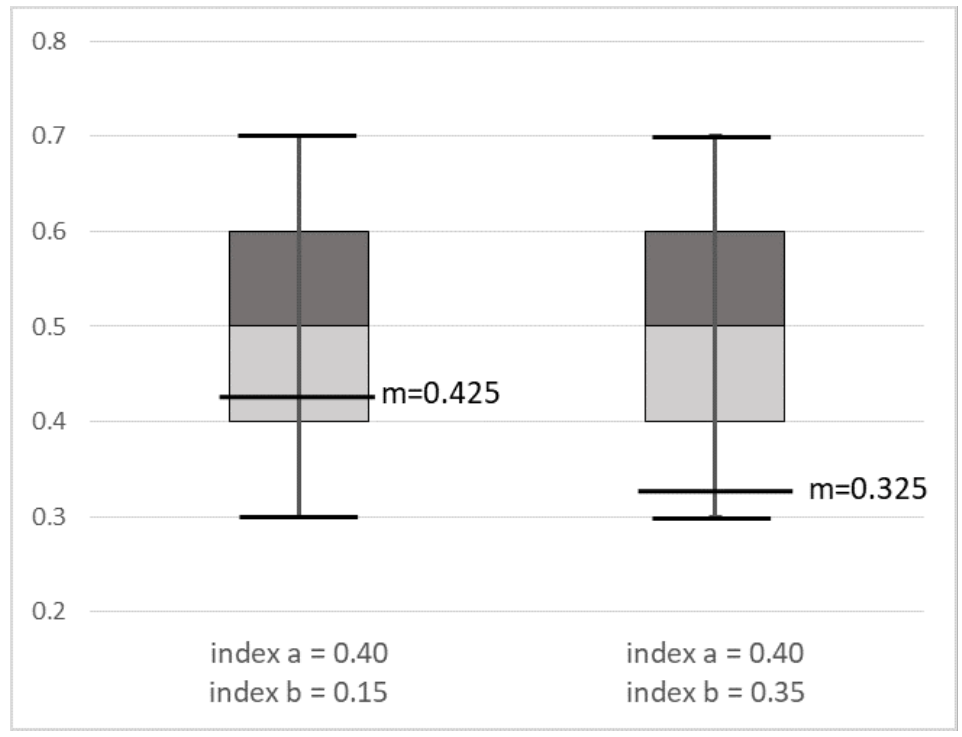


Figure 4: Ambiguity Attitudes toward Financial Sources (Averse, Neutral and Seeking)

This Figure shows the percent of investors who are ambiguity averse ( $b$-index $>0$, significant at $5 \%$ ), ambiguity neutral (cannot reject $b$-index $=0$ ), and ambiguity seeking $(b$-index $<0$, significant at $5 \%$ ) for the local stock market index (b_aex), a familiar company stock (b_stock), the MSCI World stock index (b_msci), and Bitcoin (b_bitcoin). The sample consists of $n=289$ investors.

\section{Ambiguity Attitudes}

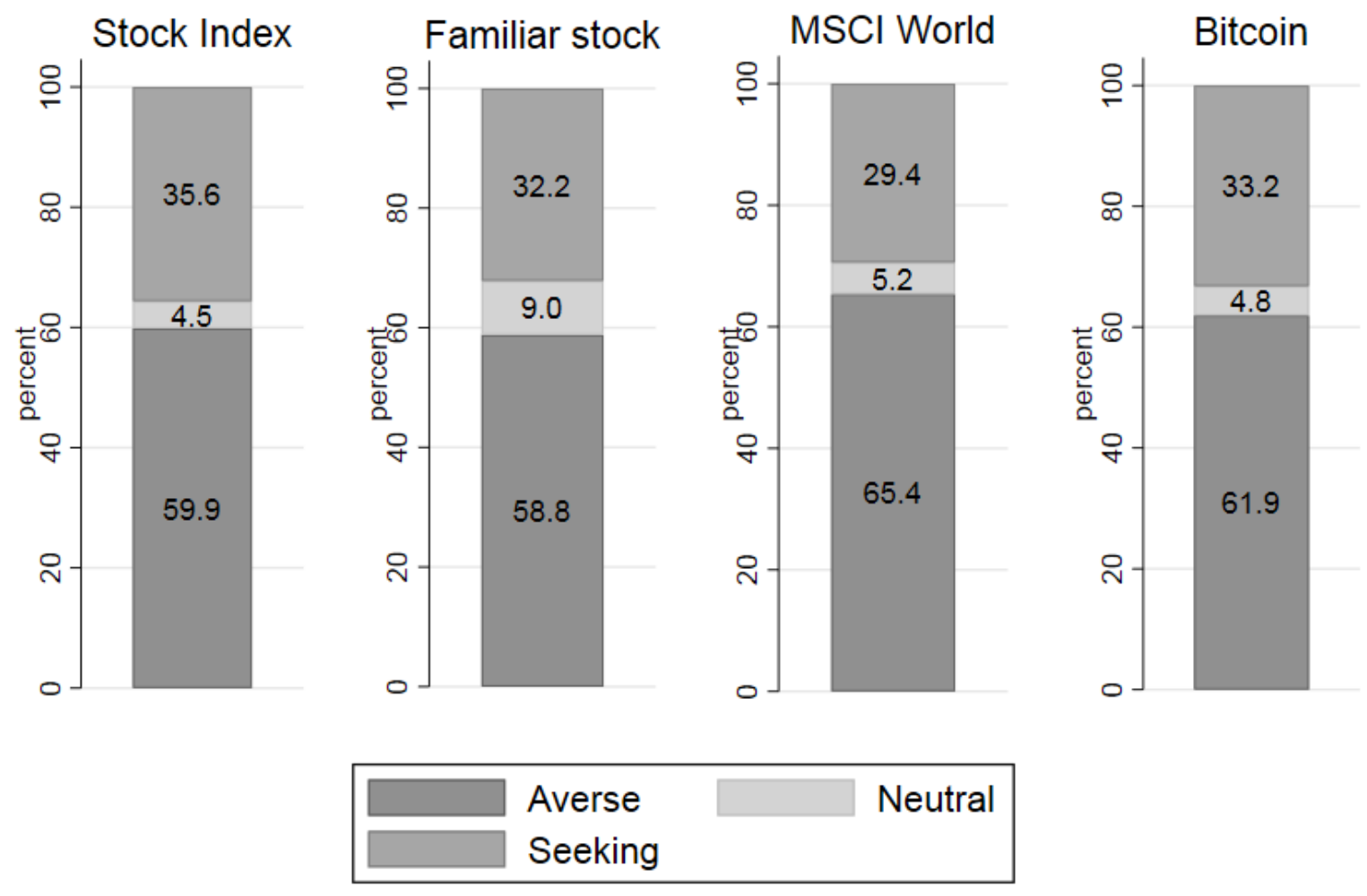




\section{Figure 5: Scatter Plots of Ambiguity Attitudes toward Different Financial Sources}

This Figure shows scatter plots of the relationships between ambiguity aversion (the $b$-indexes) for different investments: the local stock market index ( $\left.b \_a e x\right)$, a familiar company stock ( $b$ stock), the MSCI World stock index $\left(b \_m s c i\right)$, and Bitcoin $\left(b \_\right.$bitcoin). The correlation $(\mathrm{r})$ is shown above each scatter plot, with ${ }^{*},{ }^{* *},{ }^{* * *}$ denoting significance at the $10 \%, 5 \%$ and $1 \%$, respectively. The sample consists of $n=289$ investors.

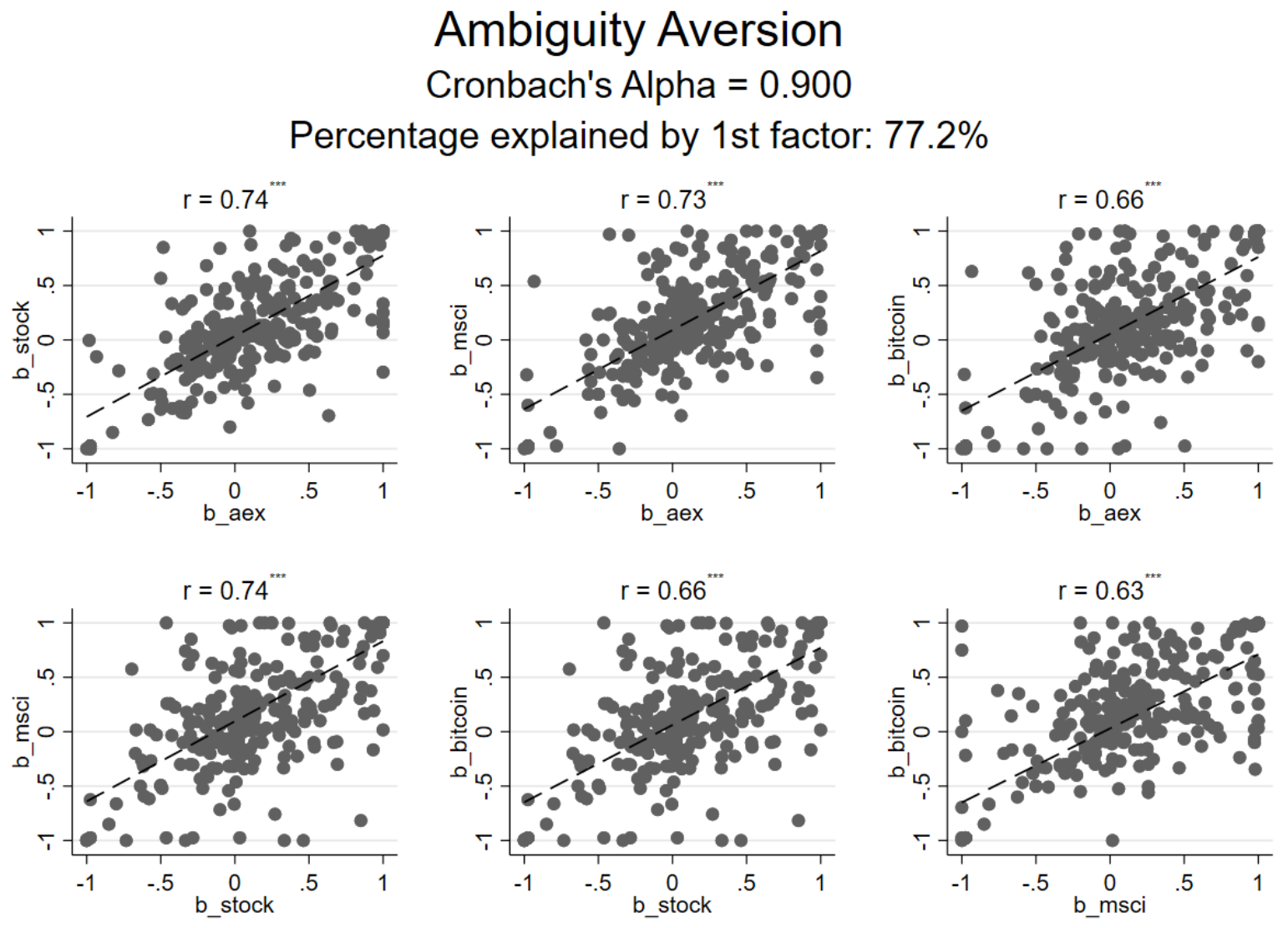




\section{Figure 6: Perceived Ambiguity about Financial Sources}

This Figure shows the percentage of investors with significant $a$-index $>0$ (perceiving ambiguity), with an insignificant $a$-index equal to 0 (who perceive no ambiguity), and significant $a$-index $<0$ (who are overly sensitive to changes in the likelihood of uncertain events), for the local stock market index (a_aex), a familiar company stock (a_stock), the MSCI World stock index (a_msci), and Bitcoin (a_bitcoin). Significance is tested with $\alpha=5 \%$. The sample consists of $n=289$ investors.

\section{Perceived Ambiguity}

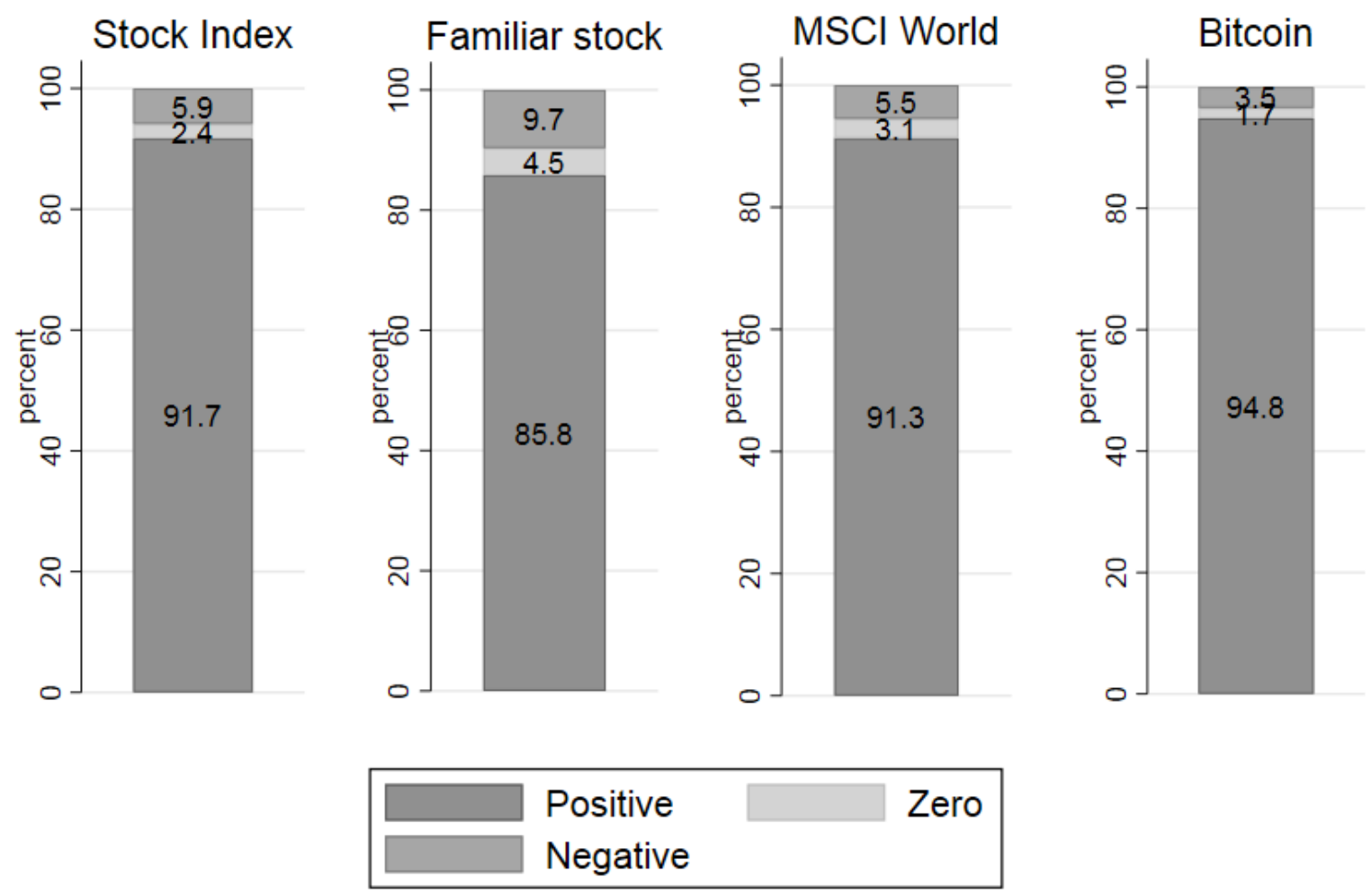




\section{Figure 7: Scatter Plots of Perceived Ambiguity about Different Financial Sources}

This Figure shows scatter plots of the relation between perceived ambiguity (the a-indexes) for different investments: the local AEX stock market index $\left(a \_a e x\right)$, a familiar company stock $\left(a \_s t o c k\right)$, the MSCI World stock index (a $m s c i)$, and Bitcoin (a bitcoin). The correlation $(\mathrm{r})$ is shown above each scatter plot, with ${ }^{*},{ }^{* *},{ }^{* * *}$ denoting significance at the $10 \%, 5 \%$ and $1 \%$, respectively. The sample consists of $n=289$ investors.

\section{Perceived Ambiguity}

\section{Cronbach's Alpha $=0.341$}

\section{Percentage explained by 1 st factor: $33.8 \%$}
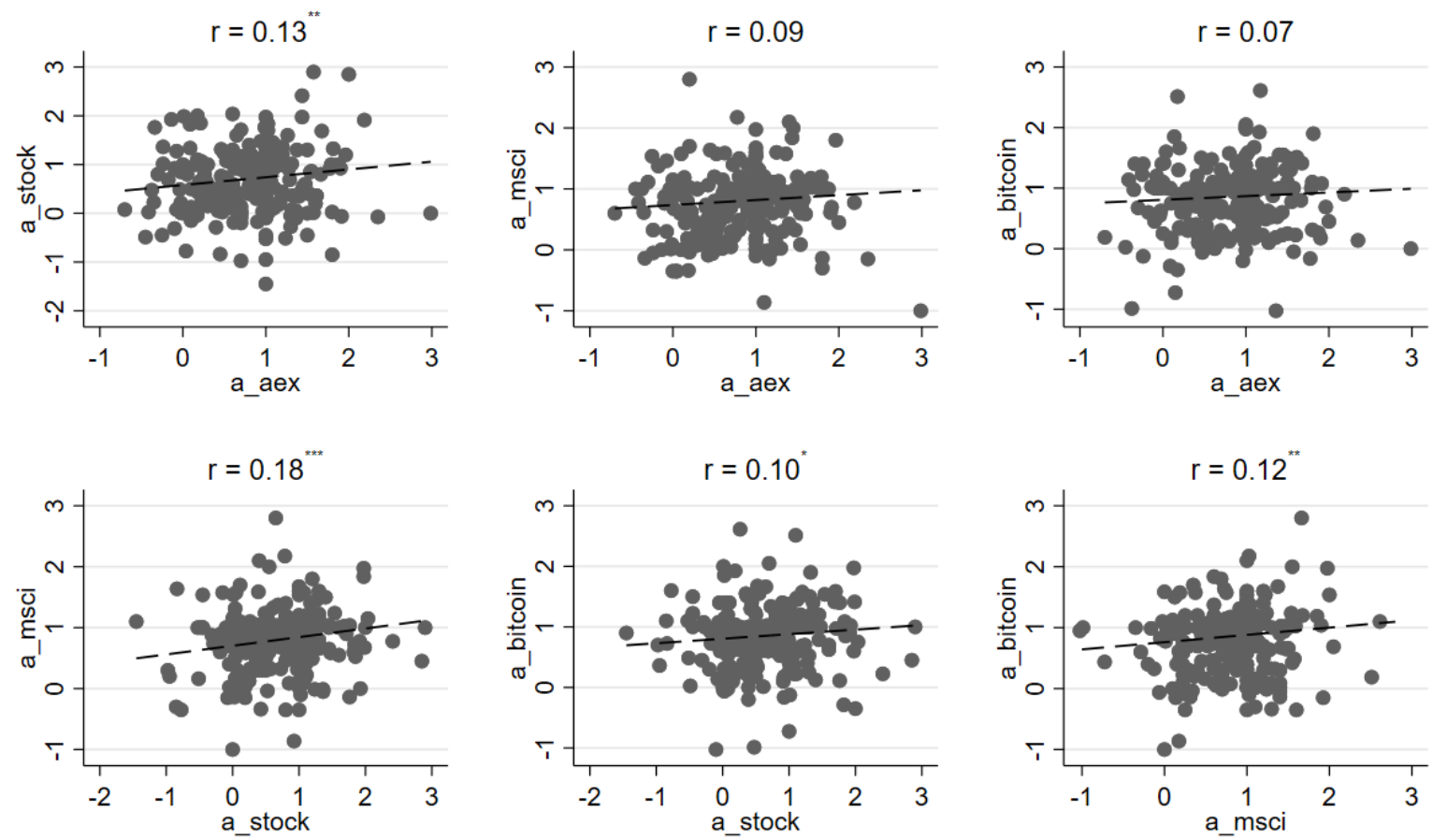


\section{Figure 8: Scatter Plots of Ambiguity Aversion versus Perceived Ambiguity}

This Figure shows scatter plots of the relation between ambiguity aversion ( $b$-index) and perceived ambiguity ( $a$-index) for each investment separately: the local AEX stock market index (b_aex vs. $\left.a \_a e x\right)$, familiar company stock (b_stock vs. $\left.a \_s t o c k\right)$, the MSCI World stock index (b_msci vs. $\left.a \_m s c i\right)$, and Bitcoin ( $b \_b i t c o i n$ vs. a bitcoin). The last scatter plot shows the relation between the average indexes for ambiguity aversion and perceived ambiguity: $b \_a v g$ vs. $a \_$avg. The correlation (r) is shown above each scatter plot, with ${ }^{*},{ }^{* *},{ }^{* * *}$ denoting significance at the $10 \%, 5 \%$ and $1 \%$, respectively. The sample consists of $n=289$ investors.

\section{Ambiguity Aversion vs Perceived Ambiguity}
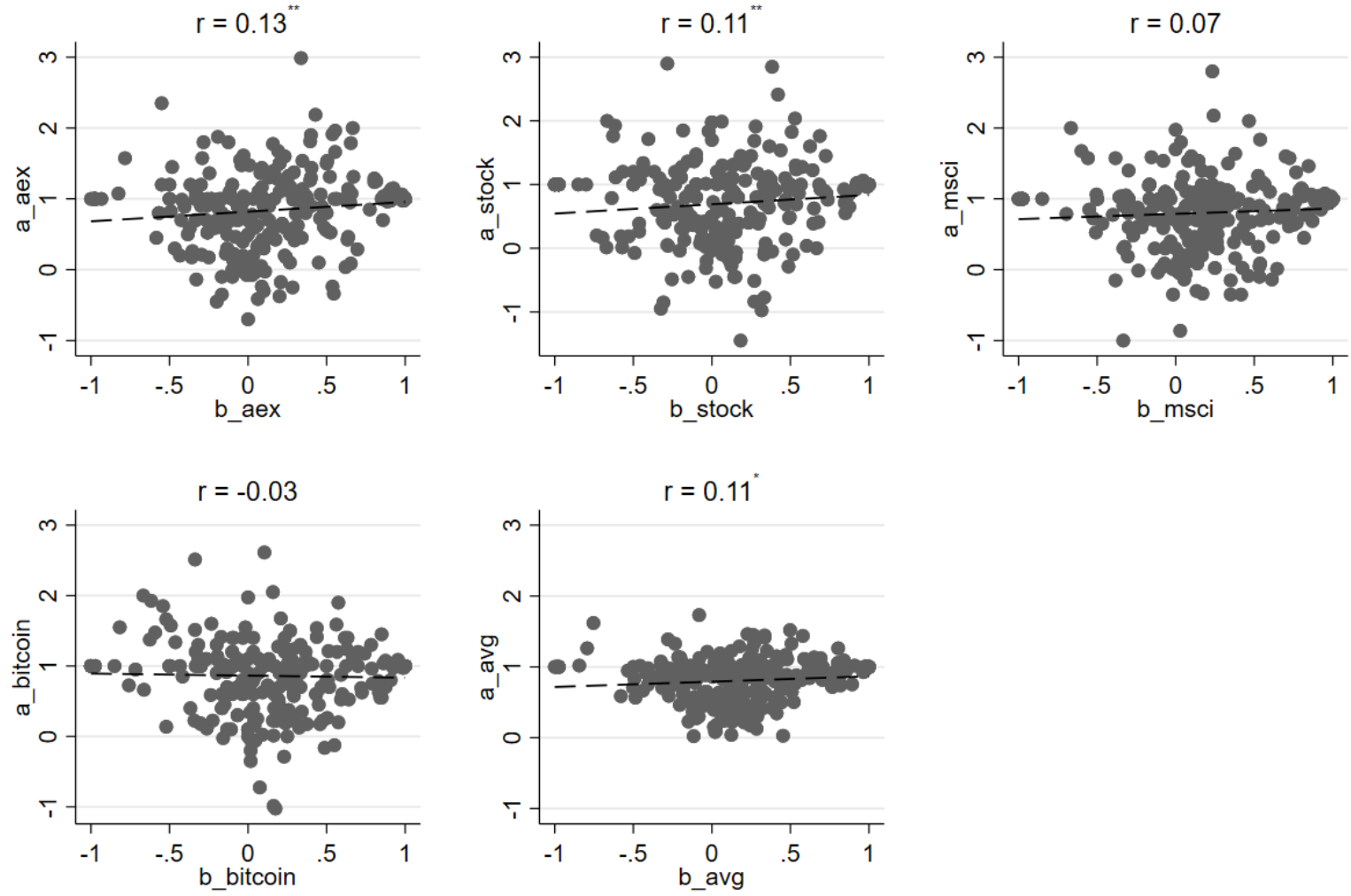


\section{Figure 9: Investment in Familiar Stock and Crypto-Currencies by Perceived Ambiguity}

The upper left figure shows the percentage of investors who invest in the familiar stock, comparing two groups with low and high perceived ambiguity about the stock ( $a$ stock $<$ median and $a$ stock $\geq$ median), while the upper right figure compares familiar stock investment percentages comparing two groups with low and high ambiguity aversion ( $b \_a v g<$ median and $b \_a v g \geq$ median). The lower left graph reports the percentage of investors who invest in crypto-currencies, comparing two groups with low and high perceived ambiguity about Bitcoin ( $a$ _bitcoin $<$ median and $a$ bitcoin $\geq$ median), while the lower right figure reports crypto-currency investments comparing two groups with low and high ambiguity aversion $\left(b \_a v g<\right.$ median and $b \_a v g \geq$ median). A two-sided p-value for a test of differences in proportions between the two groups is shown above each graph. The sample consists of $n=289$ investors.

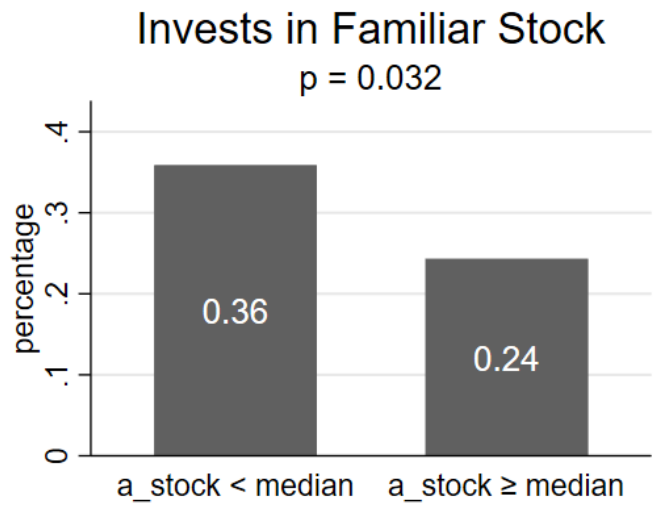

Invests in Crypto-Currencies $p=0.026$

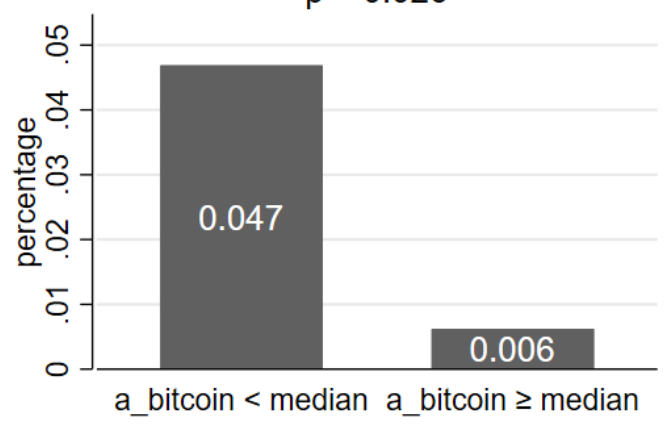

Invests in Familiar Stock $p=0.170$

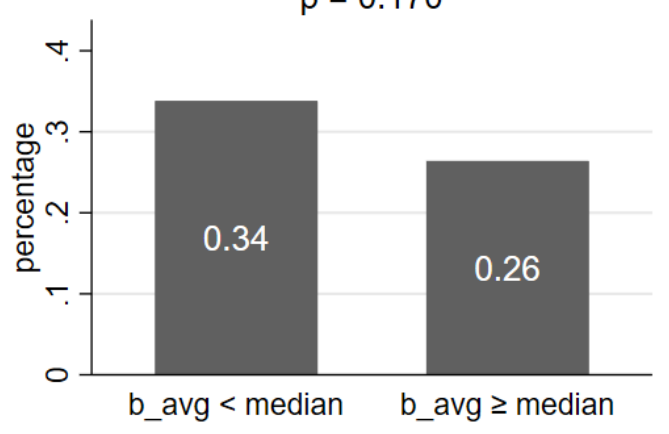

Invests in Crypto-Currencies $p=0.008$

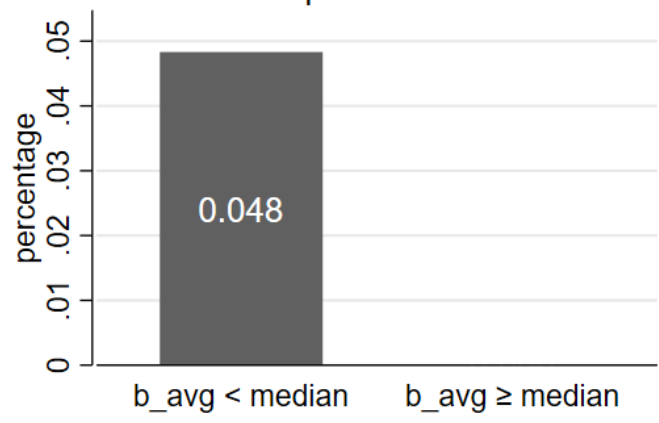


Online Appendix for

\section{Ambiguity Attitudes about Investments: \\ Evidence from the Field}

Kanin Anantanasuwong, Roy Kouwenberg, Olivia S. Mitchell, and Kim Peijnenburg

February 7, 2019 


\section{Online Appendix A. Experimental Design and Instructions}

The DHS survey module started with questions about financial literacy (see Online Appendix B) and investing, followed by choice lists for measuring risk and ambiguity attitudes. The introduction text for the risk and ambiguity questions was as follows:

INTRODUCTION

In the next few questions you will be asked several times to make a choice between Option A and Option B. After completing the survey, one of the questions you answered will be selected randomly by the computer, and your winnings will be based on the choices you have made. You could win between 0 and 15 euro, in addition to your payment for answering the survey.

The order of the risk and ambiguity choice lists was randomized, with some respondents receiving the risk questions first, and others the ambiguity questions. Two of the choice lists for eliciting risk aversion, with their instructions, are shown in Figure A1 and A2 as an example. In total there were four choice lists for risk, with chances of winning of $50 \%, 33 \%, 17 \%$, and $83 \%$. The order of the risk choice lists was randomized.

Two of the ambiguity choice lists for the AEX stock market index, with their instructions, are shown in Figure 1 and 2 of the main text. In total there were 24 choice lists for ambiguity, namely six choice lists each for four different investments (AEX, MSCI, familiar stock and Bitcoin), as explained in Section 2. The order of the four investments was randomized, as well as the order of the six events for each investment. The 24 ambiguity choice lists were always preceded by one practice question about the temperature in Amsterdam, shown in Figure A3. 


\section{Figure A1: First Choice List for Eliciting Risk Attitudes}

In this question you can win a prize depending on the result of a random coin toss. There is a $50 \%$ chance that the coin will come up heads and a 50\% chance it will come up tails. For each of the 18 rows below, please choose whether you prefer Option A or Option B.

Option A: pays off $€ 15$ if the coin comes up head (50\% chance)

Option B: A certain pay off with the amount increasing down the rows of the table.

For example, in row 1 the pay off is $€ 0.00$, in row 2 the pay off is $€ 1.00$, etc., until in row 18 the pay off is $€ 15.00$.

Please indicate whether you prefer Option A or Option B.

You do not have to make a choice in all of the 18 rows. If you select Option B in one particular row, then your choice in all following rows will automatically be set at Option B as well, and in all previous rows at Option A.

So you only have to select from which row onwards you prefer Option B.

It is also possible that you prefer Option A for every row. In that case if you select Option A in the last row, then your choice in all previous rows will automatically be set at Option A as well.

\begin{tabular}{|c|c|c|c|}
\hline $\begin{array}{l}\frac{\text { Option } \mathbf{A}}{\text { You win } € 15 \text { if the coin comes up heads }} \\
\text { (and nothing otherwise) }\end{array}$ & A & B & 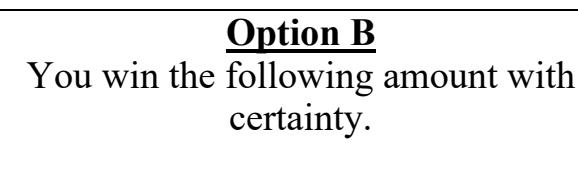 \\
\hline \multirow{18}{*}{$\begin{array}{l}\text { Heads ( } 50 \% \text { chance): You win } € 15 \text {. } \\
\text { Tails ( } 50 \% \text { chance): You win nothing. }\end{array}$} & $\mathrm{X}$ & & A certain pay off of $€ 0.00$ \\
\hline & $\mathrm{X}$ & & A certain pay off of $€ 1.00$ \\
\hline & $\mathrm{X}$ & & A certain pay off of $€ 2.00$ \\
\hline & $\mathrm{X}$ & & A certain pay off of $€ 3.00$ \\
\hline & $\mathrm{X}$ & & A certain pay off of $€ 4.00$ \\
\hline & $\mathrm{X}$ & & A certain pay off of $€ 4.50$ \\
\hline & $\mathrm{X}$ & & A certain pay off of $€ 5.00$ \\
\hline & $\mathrm{X}$ & & A certain pay off of $€ 5.50$ \\
\hline & $\mathrm{X}$ & & A certain pay off of $€ 6.00$ \\
\hline & $\mathrm{X}$ & & A certain pay off of $€ 6.50$ \\
\hline & & $\mathrm{X}$ & A certain pay off of $€ 7.00$ \\
\hline & & $\mathrm{X}$ & A certain pay off of $€ 7.50$ \\
\hline & & $\mathrm{X}$ & A certain pay off of $€ 8.00$ \\
\hline & & $\mathrm{X}$ & A certain pay off of $€ 9.00$ \\
\hline & & $\mathrm{X}$ & A certain pay off of $€ 10.00$ \\
\hline & & $\mathrm{X}$ & A certain pay off of $€ 11.00$ \\
\hline & & $\mathrm{X}$ & A certain pay off of $€ 12.50$ \\
\hline & & $\mathrm{X}$ & A certain pay off of $€ 15.00$ \\
\hline
\end{tabular}




\section{Figure A2: Second Choice List for Eliciting Risk Attitudes}

In this question you can win a prize depending on the result of a role of a dice with 6 sides, numbered from 1 to 6 , with each number equally likely. For each of the 18 rows below, please choose whether you prefer Option A or Option B.

Option A: pays off $€ 15$ if the dice comes up at number 1 or 2 (33\% chance)

Option B: A certain pay off with the amount increasing down the rows of the table.

For example, in row 1 the pay off is $€ 0.00$, in row 2 the pay off is $€ 1.00$, etc., until in row 18 the pay off is $€ 15.00$.

From which row onwards do yo prefer Option B?

\begin{tabular}{|c|c|c|c|}
\hline $\begin{array}{c}\text { Option } \mathbf{A} \\
\text { You win } € 15 \text { if the role of the dice } \\
\text { comes up as } 1 \text { or } 2 \\
\text { (and nothing otherwise) }\end{array}$ & A & B & $\begin{array}{l}\text { You win the following amount with } \\
\text { certainty. }\end{array}$ \\
\hline \multirow{18}{*}{$\begin{array}{c}\text { For } 1 \text { or } 2(33 \% \text { chance }) \text { : } \\
\text { You win } € 15 . \\
\text { For } 3,4,5 \text {, or } 6(67 \% \text { chance }) \text { : } \\
\text { You win nothing. }\end{array}$} & $\mathrm{X}$ & & A certain pay off of $€ 0.00$ \\
\hline & $\mathrm{X}$ & & A certain pay off of $€ 1.00$ \\
\hline & $\mathrm{X}$ & & A certain pay off of $€ 2.00$ \\
\hline & $\mathrm{X}$ & & A certain pay off of $€ 3.00$ \\
\hline & $\mathrm{X}$ & & A certain pay off of $€ 4.00$ \\
\hline & $\mathrm{X}$ & & A certain pay off of $€ 4.50$ \\
\hline & $\mathrm{X}$ & & A certain pay off of $€ 5.00$ \\
\hline & $\mathrm{X}$ & & A certain pay off of $€ 5.50$ \\
\hline & & $\mathrm{X}$ & A certain pay off of $€ 6.00$ \\
\hline & & $\mathrm{X}$ & A certain pay off of $€ 6.50$ \\
\hline & & $\mathrm{X}$ & A certain pay off of $€ 7.00$ \\
\hline & & $\mathrm{X}$ & A certain pay off of $€ 7.50$ \\
\hline & & $\mathrm{X}$ & A certain pay off of $€ 8.00$ \\
\hline & & $\mathrm{X}$ & A certain pay off of $€ 9.00$ \\
\hline & & $\mathrm{X}$ & A certain pay off of $€ 10.00$ \\
\hline & & $\mathrm{X}$ & A certain pay off of $€ 11.00$ \\
\hline & & $\mathrm{X}$ & A certain pay off of $€ 12.50$ \\
\hline & & $\mathrm{X}$ & A certain pay off of $€ 15.00$ \\
\hline
\end{tabular}




\section{Figure A3: Ambiguity Practice Question}

For each of the 15 rows below, please choose whether you prefer Option A or Option B.

Option A: pays off 15 euro if the temperature in Amsterdam 1 month from now at 3 p.m. is more than 20 degrees Celsius.

Option B: pays off 15 euro with a given chance, with the chance increasing down the rows of the table. For example, in row 1 the chance is $0 \%$, in row 2 the chance is $2.5 \%$, etc., until in row 15 the chance is $100 \%$.

Note: any amount you win will be paid after one month, both for Option A and Option B.

Please indicate whether you prefer Option A or Option B.

You do not have to make a choice in all of the 15 rows. If you select Option B in one particular row, then your choice in all following rows will automatically be set at Option B as well, and in all previous rows at Option A. So you only have to select from which row onwards you prefer Option B. It is also possible that you prefer Option A for every row. In that case if you select Option A in the last row, then your choice in all previous rows will automatically be set at Option $\mathrm{A}$ as well

\begin{tabular}{|c|c|c|c|}
\hline $\begin{array}{l}\text { Option } \mathbf{A} \\
\text { You win } € 15 \text { if the temperature in } \\
\text { Amsterdam } 1 \text { month from now at } 3 \mathrm{pm} \\
\text { is more than } 20 \text { degree Celsius } \\
\text { (and nothing otherwise) }\end{array}$ & A & B & $\begin{array}{l}\text { Option B } \\
\text { You win } € 15 \text { in one month time } \\
\text { with the following chance } \\
\text { (and nothing otherwise) }\end{array}$ \\
\hline \multirow{15}{*}{$\begin{array}{l}\text { A: Win } € 15 \text { if the temperature in } \\
\text { Amsterdam } 1 \text { month from now at } 3 \mathrm{pm} \\
\text { is more than } 20 \text { degree Celsius } \\
\text { (and nothing otherwise) }\end{array}$} & $\mathrm{X}$ & & B: Win $€ 15$ with chance of $0 \%$ \\
\hline & $\mathrm{X}$ & & B: Win $€ 15$ with chance of $2.5 \%$ \\
\hline & $\mathrm{X}$ & & B: Win $€ 15$ with chance of $5 \%$ \\
\hline & $\mathrm{X}$ & & B: Win $€ 15$ with chance of $10 \%$ \\
\hline & $\mathrm{X}$ & & B: Win $€ 15$ with chance of $20 \%$ \\
\hline & $\mathrm{X}$ & & B: Win $€ 15$ with chance of $30 \%$ \\
\hline & $\mathrm{X}$ & & B: Win $€ 15$ with chance of $40 \%$ \\
\hline & $\mathrm{X}$ & & B: Win $€ 15$ with chance of $50 \%$ \\
\hline & & $\mathrm{X}$ & B: Win $€ 15$ with chance of $60 \%$ \\
\hline & & $\mathrm{X}$ & B: Win $€ 15$ with chance of $70 \%$ \\
\hline & & $\mathrm{X}$ & B: Win $€ 15$ with chance of $80 \%$ \\
\hline & & $\mathrm{X}$ & B: Win $€ 15$ with chance of $90 \%$ \\
\hline & & $\mathrm{X}$ & B: Win $€ 15$ with chance of $95 \%$ \\
\hline & & $\mathrm{X}$ & B: Win $€ 15$ with chance of $97.5 \%$ \\
\hline & & $X$ & B: Win $€ 15$ with chance of $100 \%$ \\
\hline
\end{tabular}




\section{Online Appendix B. Risk Aversion and Financial Literacy}

Section B.1 defines the risk aversion measures that are used as control variables in the main text, and discusses alternative measures as a robustness check. Section B.2 lists the financial literacy questions in the DHS survey, used to create measures of basic and advanced financial literacy.

\section{B.1 Risk Aversion Measures}

The DHS module included four choice lists to measure risk attitudes (two screenshots are shown in Online Appendix A, Figure A1 and A2). The first risk attitude choice list in Figure A1 elicited a certainty equivalent for a known $50 \%$ chance of winning $€ 15$, based on a fair coin toss. The other three choice lists elicited certainty equivalents for chances of winning of $33 \%, 17 \%$, and $83 \%$, respectively, using the throw of a die. Respondents could win real money for the risk questions, and the order of the risk and ambiguity question sets in the survey was randomized. Table B1 shows summary statistics of the respondents' risk premiums for the four questions. The mean risk premiums in Table B1 display risk aversion for moderate and high probabilities $(50 \%, 87 \%)$, and risk seeking for low probabilities $(17 \%, 33 \%)$, in line with common findings in the literature (see Fehr-Duda and Epper, 2011).

\section{Table B1: Risk Premiums}

The table shows summary statistics of the investors' risk premiums for the four risk questions. The choice lists elicited a certainty equivalent for a chance of winning a prize of $€ 15$ of $50 \%, 33 \%, 17 \%$ and $88 \%$, respectively. A positive (negative) risk premium indicates that the respondent is risk averse (risk seeking), as his certainty equivalent for the risky prospect was below (above) the expected value of the prospect.

\begin{tabular}{lrrrrc} 
& Mean & Median & St dev & Min & Max \\
\hline Risk premiums & & & & & \\
Question 1: chance of winning 50\% & 0.08 & 0.03 & 0.59 & -1.00 & 1.00 \\
Question 2: chance of winning 33\% & -0.13 & -0.05 & 0.77 & -2.00 & 1.00 \\
Question 3: chance of winning 17\% & -0.77 & -0.40 & 1.60 & -5.00 & 1.00 \\
Question 4: chance of winning 87\% & 0.32 & 0.24 & 0.41 & -0.20 & 1.00 \\
\hline
\end{tabular}

Following Abdellaoui et al. (2011), we estimate index $b$ for risk as a measure of Risk Aversion and index $a$ for risk as a measure of Inverse-S probability weighting. The underlying assumptions are as follows: risk preferences are modelled with a rank-dependent utility model, using a neo-additive probability weighting function and a linear utility function.

In a rank-dependent utility model with utility function $U$ and probability weighting function $w$, indifference between the sure amount $C E_{k}$ and winning $€ 15$ with chance $p_{k}$ implies:

$$
U\left(C E_{k}\right)=w\left(p_{k}\right) U(15)+\left(1-w\left(p_{k}\right)\right) U(0), \text { for risk question } k=1,2,3,4
$$

As utility curvature is often close to linear for small amounts and risk aversion can be modelled with the probability weighting function $w$, we assume $U$ is linear with $U(x)=x$ :

(B2) $C E_{k}=w\left(p_{k}\right) 15$

The probability weighting function is of the neo-additive type as in Chateauneuf et al. (2007): 
(B3) $w(p)=c+s p$ for $0<p<1$, with $w(0)=0$ and $w(1)=1$.

The expression for the certainty equivalent in Equation (B2) now reduces to:

(B4) $\frac{C E_{k}}{15}=c+s p_{k}$

The unknown parameters $c$ and $s$ in Equation (B4) are estimated with ordinary least squares, for each respondent separately, using the four certainty equivalents. Following Abdellaoui et al. (2011), index $b$ and $a$ for risk are then defined as follows, as functions of $c$ and $s$ :

(B5) Risk Aversion $=$ index $b$ for risk $=1-s-2 c$,

(B6) Inverse- $S=$ index $a$ for risk $=1-s$.

The Risk Aversion measure captures the tendency to underweight all probabilities (pessimism). The Inverse- $S$ measure captures the tendency to overweight extreme good and bad events that occur with small known probabilities. See Figure 2 in Abdellaoui et al. (2011) for a graphic illustration of these measures. The risk attitude measures above have the advantage that they are conceptually related to index $b$ for ambiguity aversion and index $a$ for perceived ambiguity, while having an axiomatic foundation in the rank-dependent utility model with a neo-additive probability weighting function, see Cohen (1992), Chateauneuf et al. (2007), and Abdellaoui et al. (2011).

As a robustness check, we have also estimated two alternative, non-parametric, measures of risk attitudes. First, Alt. Risk Aversion is the average of the risk premiums for the two risk questions with $50 \%$ and $33 \%$ chance of winning. Alt. Inverse-S is defined as the difference in the risk premiums for the two questions with $83 \%$ and $17 \%$ chance of winning, similar to Dimmock, Kouwenberg, Mitchell, and Peijnenburg (2018). Table B2 shows the correlations between these alternative measures and the risk measures used for the main paper. Alt. Risk Aversion has a strong correlation of $r=0.9$ with Risk Aversion, implying that the two measures are highly similar. In addition, Alt. Inverse- $S$ has a correlation of $r=0.6$ with Inverse-S.

All results reported in the main text are qualitatively similar when using Alt. Risk Aversion and Alt. Inverse- $S$ as the control variables for risk attitudes in Table 3 and Table 4. For example, Table B3 shows the same analyses as Table 3 in the main text, but using the alternative risk attitude measures. The main difference is that the alternative measure of Inverse-S probability weighting has a weaker correlation with perceived ambiguity, likely because it also partially captures risk seeking attitudes (the correlation of Alt. Risk Aversion and Alt Inverse-S is -0.5). 


\section{Table B2: Correlations of Alternative Risk Attitude Measures}

The table shows correlations between the main risk attitude measures, Risk Aversion (index $b$ for risk) and Inverse-S (index $a$ for risk), and two alternative non-parametric measures: Alt. Risk Aversion and Alt. Inverse-S, defined above. The sample consists of $n=289$ investors.

\begin{tabular}{lcccc}
\hline & $(1)$ & $(2)$ & $(3)$ & $(4)$ \\
& Risk & Alt. Risk & & Alt. \\
& Aversion & Aversion & Inverse-S & Inverse-S \\
\hline Risk Aversion & 1.00 & & & \\
Alt. Risk Aversion & $0.90^{* * *}$ & 1.00 & & \\
Inverse-S & $0.28^{* * *}$ & 0.02 & 1.00 & 1.00 \\
Alt. Inverse-S & $-0.52^{* * *}$ & $-0.51^{* * *}$ & $0.58^{* * *}$ & \\
\hline
\end{tabular}




\section{Table B3: Factors Associated with Ambiguity Attitudes}

Panel A shows correlations of ambiguity aversion (b_avg) and perceived ambiguity ( $\left.a \_a v g\right)$ with financial literacy, education, and the alternative measures of risk aversion and Inverse-S. Panel B shows standardized beta coefficients from regression models of ambiguity aversion and perceived ambiguity regarding financial sources. In Column (1), the dependent variable is $b \_a v g$, the index of ambiguity aversion averaged over the four financial sources (aex, stock, msci and bitcoin). In Column (2), the dependent variable is $a \_a v g$, the index of perceived ambiguity averaged over the four financial sources (aex, stock, msci and bitcoin). In Panel B, the controls are financial literacy (total score), education, the alternative risk aversion and Inverse-S measures, age, gender, single, an indicator for employment, the logarithm of the number of children living at home, family income, and household financial wealth, plus a control for missing wealth. The sample consists of $n=289$ investors. ${ }^{*},{ }^{* *},{ }^{* * *}$ denote significant coefficients at the $10 \%, 5 \%$ and $1 \%$ level.

Panel A: Correlations with Financial Literacy, Education and Risk Attitudes

\begin{tabular}{lcc}
\hline & $(1)$ & $(2)$ \\
& Ambiguity & Perceived \\
& Aversion & Ambiguity \\
& $b \_a v g$ & $a \_a v g$ \\
\hline Financial Literacy & -0.09 & $-0.21^{* * *}$ \\
Education & $-0.10^{*}$ & $-0.27^{* * *}$ \\
Alt. Risk Aversion & $0.49^{* * *}$ & -0.01 \\
Alt. Inverse-S & $-0.27^{* * *}$ & $0.13^{* *}$ \\
\hline
\end{tabular}

Panel B: Multiple Regression Models

\begin{tabular}{|c|c|c|}
\hline & $\begin{array}{c}(1) \\
\text { Ambiguity } \\
\text { Aversion } \\
b \text { avg }\end{array}$ & $\begin{array}{c}(2) \\
\text { Perceived } \\
\text { Ambiguity } \\
a \text { avg }\end{array}$ \\
\hline Financial Literacy & -0.058 & $-0.132^{* * *}$ \\
\hline Education & -0.062 & $-0.210^{* * *}$ \\
\hline Alt. Risk Aversion & $0.427^{* * *}$ & 0.027 \\
\hline Alt. Inverse-S & -0.082 & 0.105 \\
\hline Age & $0.125^{*}$ & 0.120 \\
\hline Female & 0.042 & -0.057 \\
\hline Single & -0.081 & -0.070 \\
\hline Employed & -0.052 & -0.025 \\
\hline Number of kids (log) & 0.038 & 0.011 \\
\hline Family Income (log) & 0.043 & $-0.103^{* *}$ \\
\hline Financial Wealth $(\log )$ & -0.056 & 0.066 \\
\hline $\mathrm{R}^{2}$ & 0.293 & 0.142 \\
\hline $\mathrm{N}$ & 289 & 289 \\
\hline
\end{tabular}




\section{B.2 Financial Literacy Questions}

The financial literacy questions are taken from Lusardi and Mitchell (2007) and Van Rooij, Lusardi, and Alessie (2011). Responses to the financial literacy questions were provided by the DHS (Centerdata), collected in a 2017 survey. For respondents with missing financial literacy data, these questions were included in our own DHS survey module.

The questions were preceded by the following instructions: "The following 12 questions are about financial knowledge and investments. Please do not look up information and do not use a calculator. Your initial thought matters." Apart from the possible answers shown below each question, respondents could also choose "I do not know" and "Refuse to answer" as a response.

FL1: Suppose you had 100 euro in a savings account and the interest rate was 2\% per year. After 5 years, how much do you think you would have in the account if you left the money to grow?

1. More than 102 euro

2. Exactly 102 euro

3. Less than 102 euro

FL2: Assume a friend inherits euro 10,000 today and his sibling inherits 10,000 euro 3 years from now. Who is richer because of the inheritance?
1. My friend
2. His sibling
3. They are equally rich

FL3: Suppose that in the year 2018, your income has doubled and prices of all goods have doubled too. In 2018, how much will you be able to buy with your income?

1. More than today

2. The same

3. Less than today

FL4: Suppose that you have 100 euro in a savings account and the interest is 20\% per year, and you never withdraw the money or interest. How much do you have on the account after 5 years?

1. More than 200 euro

2. Exactly 200 euro

3. Less than 200 euro

FL5: Suppose the interest on your savings account is 1\% per year and the inflation is 2\% per year. After 1 year, can you buy more, exactly the same, or less than today with the money on the account?

1. More than today

2. Exactly the same as today

3. Less than today

FL6: Is the following statement true, or not true?

"A company stock usually provides a less risky return than an equity mutual fund."

1. True

2. Not true 
FL7: Which of the following statements describes the main function of the stock market?

1. The stock market helps to predict stock earnings

2. The stock market results in an increase in the price of stocks

3. The stock market brings people who want to buy stocks together with those who want to sell stocks

4. None of the above

FL8: Which of the following statements is correct? If somebody buys the stock of firm B in the stock market:

1. He owns a part of firm $B$

2. He has lent money to firm $B$

3. He is liable for firm $B$ 's debts

4. None of the above

FL9: Which of the following statements is correct?

1. If one invests in a mutual fund, one cannot withdraw the money in the first year

2. Mutual funds can invest in several assets, for example invest in both stocks and bonds

3. Mutual funds pay a guaranteed rate of return which depends on their past performance

4. None of the above

FL10: Normally, which asset displays the highest fluctuations over time: a savings account, bonds or stocks?

1. Savings accounts

2. Bonds

3. Stocks

FL11: When an investor spreads his money among different assets, does the risk of losing money: increase, decrease, or stay the same?

1. Increase

2. Decrease

3. Stay the same

FL12: Is the following statement true, or not true? 'Stocks are normally riskier than bonds.'

1. Yes

2. No 


\section{Online Appendix C. Robustness Checks}

Section C.1 first summarizes the main results of the paper after screening out investors who violate monotonicity conditions, or who make several mistakes on the ambiguity questions. Then Section C.2 summarizes the results for a separate group, non-investors, who are not included in the main paper. In sum, the results are similar to the findings presented in the body of the main paper.

\section{C.1 Excluding investors who make errors on the ambiguity questions}

As a robustness check, we exclude 109 investors who violate the monotonicity condition ( $a$ avg $>1$ ) or who make more than three errors on any ambiguity question set of 6 choice lists. Respondents could make two errors on each choice list: always choosing Option A, or always choosing Option B. There are 180 investors left $(62.3 \%)$ in this restricted sample of respondents with more consistent responses to the ambiguity questions.

The proportion of ambiguity averse, neutral, and seeking respondents are $63 \%, 4 \%, 33 \%$, respectively, based on $b \_a v g$. These proportions are not significantly different from the full sample $(66 \%, 4 \%, 30 \%)$, illustrating that ambiguity averse and ambiguity seeking attitudes are not driven by respondents making errors on the choice lists. Table $\mathrm{C} 1$ shows summary statistics for the ambiguity attitude measures ( $n=180$; restricted sample). In the restricted sample, the mean level of ambiguity aversion and perceived ambiguity are lower at 0.13 and 0.69 , compared to 0.18 and 0.80 in the full sample, arguably because investors making less errors on the ambiguity questions have less extreme measurements.

Table C2 shows correlation of the ambiguity attitude measures. In the restricted sample, ambiguity aversion is still driven by a single factor explaining $77 \%$ of the variation, with Cronbach's alpha of 0.90 . The means of the $b$-indexes are not significantly different $\left(T^{2}=5.35, \mathrm{p}=0.156\right)$. Perceived ambiguity still differs between sources, even for the same individual: the first factor can explain $29 \%$ of the variation, with Cronbach's alpha of 0.14 . The means of the a-indexes are significantly different $\left(T^{2}=14.16, \mathrm{p}=0.004\right)$.

In the multiple regression models explaining ambiguity attitudes, shown in Table C3, risk aversion is the only significant driver of ambiguity aversion in the restricted sample $\left(\mathrm{R}^{2}=23 \%\right)$. Further, when explaining perceived ambiguity, the betas of financial literacy, education, Inverse-S, and income are now all significant at the $1 \%$ level, with higher effect sizes than before $\left(\mathrm{R}^{2}=35 \%\right)$.

When explaining investment in the familiar stock, the results in Table $\mathrm{C} 4$ for the restricted sample are similar to the full sample: perceived ambiguity is significant at the $5 \%$ level without controls, but insignificant with controls. When explaining investment in crypto-currencies, $a$ bitcoin is no longer significant, but $b \_a v g$ is still significant at the $1 \%$ level without controls (but insignificant with controls). 


\section{C.2 Results for non-investors}

Our survey was also given to a random sample of 304 non-investors, with 225 complete and valid responses $(74 \%)$. Compared to the investors, the non-investors are younger, less educated, more often female, have less financial wealth, and lower financial literacy.

The proportion of ambiguity averse, neutral, and seeking non-investors are $69 \%, 5 \%, 26 \%$ based on $b \_a v g$, which is not significantly different from the investor group $(66 \%, 4 \%, 30 \%)$. Table C5 displays summary statistics of the ambiguity attitudes for the non-investor group. Additional tests show that the mean of ambiguity aversion $\left(b \_a v g\right)$ is not different between the groups of investors and non-investors $(0.18$ vs. $0.20, \mathrm{p}=0.63)$. However, the average level of perceived ambiguity $\left(a \_a v g\right)$ is higher for non-investors $(0.88$ vs. $0.80, \mathrm{p}=0.01)$, as expected. Hence, ambiguity preferences toward financial assets are not significantly different between investors and noninvestors on average, but the level of perceived ambiguity is.

Among non-investors, ambiguity aversion is driven by a single factor explaining $83 \%$ of the variation, with Cronbach's alpha of 0.93 . The means of the $b$-indexes are not significantly different $\left(T^{2}=6.21, \mathrm{p}=0.11\right)$. Perceived ambiguity does vary between sources for the same individual: the first factor can explain only $40 \%$ of the variation in the a-indexes, with Cronbach's alpha of 0.49 . These results are similar to the investor group. The only difference is that among non-investors the mean of perceived ambiguity ( $a$-indexes) for the four financial assets is not significantly different $\left(T^{2}=4.43, \mathrm{p}=0.23\right)$.

The correlations of ambiguity attitudes with other variables (Table 3 in the main paper) are similar for investors and non-investors, except that in the non-investor group ambiguity aversion ( $b a v g$ ) also has a significant negative correlation with financial literacy $(r=-0.24)$ and education level $(r=-0.19)$. In multiple regressions, similar to Panel B of Table 3, ambiguity aversion is positively related to risk aversion and age, and negatively related to financial literacy $(p=0.01)$. When explaining perceived ambiguity in Column (3), the betas of financial literacy, Inverse-S, income and the dummies for employment and female are significant $\left(\mathrm{R}^{2}=16 \%\right)$. Hence, in the noninvestor group, ambiguity aversion is negatively related to financial knowledge. However, this effect is not robust when excluding respondents who make errors on the ambiguity questions. After excluding respondents who violate monotonicity or make several errors (similar to Section C.1), the only significant drivers of ambiguity aversion are risk aversion and age $\left(\mathrm{R}^{2}=36 \%\right)$, while perceived ambiguity is best explained by Inverse-S probability weighting and income $\left(\mathrm{R}^{2}=25 \%\right)$. 
Table C1: Descriptive Statistics for Ambiguity Measures - Restricted Sample

Panel A shows summary statistics for ambiguity attitudes regarding the local stock market index ( $\left.b \_a e x\right)$, a familiar company stock ( $\left.b \_s t o c k\right)$, the MSCI World stock index ( $\left.b \_m s c i\right)$ and Bitcoin $\left(b \_\right.$bitcoin $)$, as well as the average of the four b-indexes $\left(b_{-} a v g\right)$. Positive values of the $b$-index denote ambiguity aversion, and negative values indicate ambiguity seeking. Panel B shows summary statistics for the perceived ambiguity indexes regarding the local stock market index ( $\left.a \_a e x\right)$, a familiar company stock ( $\left.a \_s t o c k\right)$, the MSCI World stock index ( $\left.a \_m s c i\right)$ and Bitcoin ( $a$ _bitcoin), as well as the average of the four $a$-indexes ( $a$ avg). Positive values of the $a$-index denote perceived ambiguity. The sample is restricted to $n=180$ investors who did not violate the monotonicity condition $\left(a \_a v g \leq 1\right)$ and made three or less errors on any ambiguity question set of 6 choice lists. In Panel A, Hotelling's $T^{2}$ tests the null hypothesis that the means of the four ambiguity attitude measures are equal for $b \_a e x, b \_s t o c k, b \_m s c i$ and $b \_b i t c o i n$. In Panel B, Hotelling's $T^{2}$ tests whether the means of the four perceived ambiguity measures are equal for $a \_a e x$, $a \_$stock, $a \_m s c i$ and $a \_b i t c o i n$.

Panel A: Ambiguity Aversion

\begin{tabular}{lccccc}
\hline & Mean & Median & St dev & Min & Max \\
\hline b_aex & 0.11 & 0.09 & 0.43 & -0.98 & 0.99 \\
b_stock & 0.11 & 0.04 & 0.45 & -0.98 & 0.99 \\
b_msci & 0.16 & 0.11 & 0.42 & -0.98 & 0.99 \\
b_bitcoin & 0.14 & 0.10 & 0.44 & -0.98 & 0.98 \\
b_avg & 0.13 & 0.10 & 0.38 & -0.98 & 0.98 \\
Test of equal means: Hotelling's $T^{2}=5.35, p=0.1561$ & & \\
\hline
\end{tabular}

Panel B: Perceived Ambiguity

\begin{tabular}{|c|c|c|c|c|c|}
\hline & Mean & Median & St dev & Min & Max \\
\hline$a \_a e x$ & 0.75 & 0.90 & 0.51 & -0.70 & 2.35 \\
\hline a_stock & 0.58 & 0.61 & 0.56 & -0.98 & 1.92 \\
\hline$a \_m s c i$ & 0.67 & 0.77 & 0.46 & -0.86 & 1.70 \\
\hline a_bitcoin & 0.76 & 0.90 & 0.47 & -1.02 & 2.51 \\
\hline$a \_a v g$ & 0.69 & 0.73 & 0.26 & 0.02 & 1.00 \\
\hline \multicolumn{6}{|c|}{ Test of equal means: Hotelling's $T^{2}=14.16, p=0.0036$} \\
\hline
\end{tabular}




\section{Table C2: Correlations of Ambiguity Measures - Restricted Sample}

Panel A shows pairwise correlations of the ambiguity attitude indexes for the local stock market index ( $b a e x)$, a familiar company stock (b_stock), the MSCI World stock index (b_msci), and Bitcoin (b_bitcoin), as well as the average of the b-indexes $\left(b_{a} a v g\right)$. Panel B shows correlations of the perceived ambiguity indexes for the local stock market index (a_aex), a familiar company stock (a_stock), the MSCI World stock index $(a$ msci) and Bitcoin ( $a$ _bitcoin), as well as the average of the a-indexes ( $\left.a \_a v g\right)$. The sample is restricted to $n=180$ investors who did not violate the monotonicity condition $\left(a \_a v g \leq 1\right)$ and made three or less errors on any ambiguity question set of 6 choice lists. The last two rows of Panels A and B show the percentage of variation in the four ambiguity measures (aex, stock, msci and bitcoin) explained by the $1^{\text {st }}$ factor in a factor analysis, as well as Cronbach's alpha of the four measures (aex, stock, msci and bitcoin). ${ }^{*},{ }^{* *},{ }^{* * *}$ denote significant correlations at the $10 \%, 5 \%$ and $1 \%$ level.

Panel A: Correlations of Ambiguity Aversion

\begin{tabular}{llllll} 
& b_aex & b_stock & b_msci & b_bitcoin & b avg \\
\hline b_aex & 1.00 & & & & $0.88^{* * *}$ \\
b_stock & $0.74^{* * *}$ & 1.00 & & & $0.91^{* * *}$ \\
b_msci & $0.73^{* * *}$ & $0.74^{* * *}$ & 1.00 & & $0.88^{* * *}$ \\
b_bitcoin & $0.59^{* * *}$ & $0.68^{* * *}$ & $0.63^{* * *}$ & 1.00 & $0.83^{* * *}$
\end{tabular}

Percentage explained by $1^{\text {st }}$ factor: $76.5 \%$

Cronbach's alpha: 0.897

Panel B: Correlations of Perceived Ambiguity

\begin{tabular}{llllll} 
& a_aex & a_stock & a_msci & a_bitcoin & a_avg \\
\hline a_aex & 1.00 & & & & $0.51^{* * *}$ \\
a_stock & 0.00 & 1.00 & & & $0.64^{* * *}$ \\
a_msci & 0.06 & $0.14^{*}$ & 1.00 & & $0.48^{* * *}$ \\
a_bitcoin & 0.00 & 0.12 & -0.11 & 1.00 & $0.46^{* * *}$
\end{tabular}

Percentage explained by $1^{\text {st }}$ factor: $28.9 \%$

Cronbach's alpha: 0.139 


\section{Table C3: Factors Associated with Ambiguity Attitudes - Restricted Sample}

Panel A shows correlations of ambiguity aversion (b_avg) and perceived ambiguity ( $\left.a \_a v g\right)$ with financial literacy, education, risk aversion, and Inverse-S probability weighting. Panel B shows standardized beta coefficients from regression models of ambiguity aversion and perceived ambiguity regarding financial sources. In Column (1), the dependent variable is $b \_a v g$, the index of ambiguity aversion averaged over the four financial sources (aex, stock, msci and bitcoin). In Column (2), the dependent variable is $a \_a v g$, the index of perceived ambiguity averaged over the four financial sources (aex, stock, msci and bitcoin). In Panel B, the controls are financial literacy (total score), education, risk aversion, Inverse-S probability weighting, age, gender, single, an indicator for employment, the logarithm of the number of children living at home, family income, and household financial wealth, plus a control for missing wealth. The sample is restricted to $n=180$ investors who did not violate the monotonicity condition (a_avg $\leq 1$ ) and made three or less errors on any ambiguity question set of 6 choice lists. ${ }^{*},{ }^{* *},{ }^{* * *}$ denote significant coefficients at the $10 \%, 5 \%$ and $1 \%$ level.

\section{Panel A: Correlations with Financial Literacy, Education and Risk Attitudes}

\begin{tabular}{lcc} 
& $(1)$ & $(2)$ \\
& Ambiguity & Perceived \\
& Aversion & Ambiguity \\
& $b_{a}$ avg & $-0.23^{* * *}$ \\
\hline Financial Literacy & -0.07 & $-0.13^{*}$ \\
Education & -0.12 & 0.10 \\
Risk Aversion & $0.41^{* * *}$ & $0.26^{* * *}$ \\
Inverse-S & $0.13^{*}$ & \\
\hline
\end{tabular}

Panel B: Multiple Regression Models

\begin{tabular}{lcc} 
& $(1)$ & $(2)$ \\
& $\begin{array}{c}\text { Ambiguity } \\
\text { Aversion }\end{array}$ & $\begin{array}{c}\text { Perceived } \\
\text { Ambiguity } \\
\text { a_avg }\end{array}$ \\
\hline Financial Literacy & -0.048 & $-0.213^{* * *}$ \\
Education & -0.015 & $-0.263^{* * *}$ \\
Risk Aversion & $0.404^{* * *}$ & $-0.051^{* * *}$ \\
Inverse-S & -0.033 & $0.348^{* * *}$ \\
Age & 0.135 & 0.045 \\
Female & $0.126^{*}$ & -0.061 \\
Single & $-0.147^{*}$ & -0.061 \\
Employed & 0.049 & 0.013 \\
Number of kids $(\log )$ & -0.044 & -0.038 \\
Family Income $(\log )$ & -0.025 & $-0.140^{* * *}$ \\
Financial Wealth $(\log )$ & -0.047 & 0.081 \\
\hline $\mathrm{R}^{2}$ & 0.230 & 0.346 \\
$\mathrm{~N}$ & 180 & 180 \\
\hline
\end{tabular}




\section{Table C4: Investment in Familiar Stock and Crypto-Currency - Restricted Sample}

This table reports estimated results for investing in a familiar stock (columns 1 and 2) and investing in crypto-currency (columns 3 and 4). The numbers displayed are percent changes in the odds ratio $(\exp (\beta)-1)$ of investing in the asset based on estimated coefficients $(\beta)$ from a logistic regression model. In Columns (1) and (2), the dependent variable is 1 if the respondent invests in the familiar individual stock and 0 otherwise. In Columns (3) and (4), the dependent variable is 1 if the respondent invests in crypto-currency and 0 otherwise. Independent variables include $b \_a v g$, the overall index of ambiguity aversion averaged over the four financial sources (aex, stock, msci and bitcoin), as well as perceived ambiguity about the familiar stock (a_stock) and perceived ambiguity about Bitcoin $\left(a \_\right.$bitcoin). In Column (2) and (4), a limited set of control variables is included. Discrete control variables such as gender and education are omitted to avoid problems with complete separation (when a discrete explanatory variable completely separates the dependent variable). The sample is restricted to $n=180$ investors who did not violate the monotonicity condition $\left(a \_a v g \leq 1\right)$ and made three or less errors on any ambiguity question set of 6 choice lists. ${ }^{*},{ }^{* *},{ }^{* * *}$ denote significant coefficients at the $10 \%, 5 \%$ and $1 \%$ level.

\begin{tabular}{|c|c|c|c|c|}
\hline & \multicolumn{2}{|c|}{$\begin{array}{l}\text { Investment in } \\
\text { Familiar Stock }\end{array}$} & \multicolumn{2}{|c|}{$\begin{array}{c}\text { Investment in } \\
\text { Crypto-Currencies }\end{array}$} \\
\hline & $(1)$ & $(2)$ & $(3)$ & (4) \\
\hline a_stock & $-0.473^{* *}$ & $-0.479^{*}$ & & \\
\hline a_bitcoin & & & -0.465 & -0.472 \\
\hline$b \_a v g$ & -0.484 & $-0.706^{*}$ & $-0.681^{* * *}$ & -0.803 \\
\hline Financial Literacy & & 0.090 & & 0.062 \\
\hline Risk Aversion & & $1.812^{*}$ & & 0.357 \\
\hline Inverse-S & & 0.478 & & 0.49 \\
\hline Age & & -0.005 & & $-0.139^{* * *}$ \\
\hline Family Income (log) & & 0.152 & & -0.156 \\
\hline Financial Wealth $(\log )$ & & $0.237^{* *}$ & & 0.102 \\
\hline Pseudo $\mathrm{R}^{2}$ & 0.033 & 0.097 & 0.026 & 0.387 \\
\hline $\mathrm{N}$ & 180 & 180 & 180 & 180 \\
\hline
\end{tabular}


Table C5: Descriptive Statistics for Ambiguity Measures - Non-Investor Sample

Panel A shows summary statistics for ambiguity attitudes regarding the local stock market index ( $b$ a $a e x)$, a familiar company stock $\left(b \_s t o c k\right)$, the MSCI World stock index ( $\left.b \_m s c i\right)$ and Bitcoin $\left(b \_b i t c o i n\right)$, as well as the average of the four b-indexes $(\bar{b} a v g)$. Positive values of the $b$-index denote ambiguity aversion, and negative values indicate ambiguity seeking. Panel B shows summary statistics for the perceived ambiguity indexes regarding the local stock market index (a_aex), a familiar company stock (a_stock), the MSCI World stock index (a_msci) and Bitcoin (a_bitcoin), as well as the average of the four $a$-indexes (a_avg). Positive values of the $a$-index denote perceived ambiguity. The sample consists of $n=225$ non-investors. In Panel A, Hotelling's $T^{2}$ tests the null hypothesis that the means of the four ambiguity attitude measures are equal for $b$ aex, $b$ stock, $b$ msci and $b$ bitcoin. In Panel $\mathrm{B}$, Hotelling's $T^{2}$ tests whether the means of the four perceived ambiguity measures are equal for $a \_a e x, a \_s t o c k, a \_m s c i$ and a_bitcoin.

Panel A: Ambiguity Aversion

\begin{tabular}{lccccc} 
& Mean & Median & St dev & Min & Max \\
\hline b_aex & 0.20 & 0.20 & 0.51 & -1.00 & 1.00 \\
b_stock & 0.23 & 0.23 & 0.55 & -1.00 & 1.00 \\
b_msci & 0.19 & 0.15 & 0.52 & -1.00 & 1.00 \\
b_bitcoin & 0.17 & 0.10 & 0.55 & -1.00 & 1.00 \\
b_avg & 0.20 & 0.17 & 0.48 & -1.00 & 1.00 \\
Test of equal means: Hotelling's $T^{2}=6.21, p=0.1075$ & & \\
\hline
\end{tabular}

Panel B: Perceived Ambiguity

\begin{tabular}{|c|c|c|c|c|c|}
\hline & Mean & Median & St dev & Min & Max \\
\hline$a \_a e x$ & 0.91 & 1.00 & 0.50 & -1.00 & 2.35 \\
\hline a_stock & 0.82 & 1.00 & 0.52 & -0.95 & 2.38 \\
\hline$a \_m s c i$ & 0.89 & 1.00 & 0.44 & -0.74 & 2.14 \\
\hline a_bitcoin & 0.89 & 1.00 & 0.49 & -0.65 & 2.95 \\
\hline a_avg & 0.88 & 0.96 & 0.31 & 0.14 & 1.84 \\
\hline \multicolumn{6}{|c|}{ Test of equal means: Hotelling's $T^{2}=4.43, p=0.2256$} \\
\hline
\end{tabular}




\section{Online Appendix References}

Abdellaoui, M., Baillon, A., Placido, L., \& Wakker, P. P. (2011). The rich domain of uncertainty: Source functions and their experimental implementation. American Economic Review, 101(2), 695-723.

Chateauneuf, A., Eichberger, J., \& Grant, S. (2007). Choice under uncertainty with the best and worst in mind: Neo-additive capacities. Journal of Economic Theory, 137(1), 538-567.

Cohen, M. (1992). Security level, potential level, expected utility: A three-criteria decision model under risk. Theory and Decision, 33(2), 101-134.

Dimmock, S. G., Kouwenberg, R., Mitchell, O. S., \& Peijnenburg, K. (2018). Household portfolio underdiversification and probability weighting: Evidence from the field. Working paper, National Bureau of Economic Research (No. w24928).

Fehr-Duda, H., \& Epper, T. (2011). Probability and risk: Foundations and economic implications of probability-dependent risk preferences. Annual Review of Economics, 4(1), 567-593

Lusardi, A., \& Mitchell, O.S. (2007). Baby Boomers' retirement security: The role of planning, financial literacy and housing wealth. Journal of Monetary Economics 54(1), 205-224.

Van Rooij, M., Lusardi, A., \& Alessie, R. (2011). Financial literacy and stock market participation. Journal of Financial Economics, 101(2), 449-472. 